\title{
Vicerrectorado de Investigación
}

GUÍA DE PRODUCTOS OBSERVABLES DE INVESTIGACIÓN DE LA UNIVERSIDAD PRIVADA NORBERT WIENER 


\section{Universidad Privada Norbert Wiener}

\section{Guía de Productos Observables de}

\section{Investigación de la Universidad Privada}

Norbert Wiener

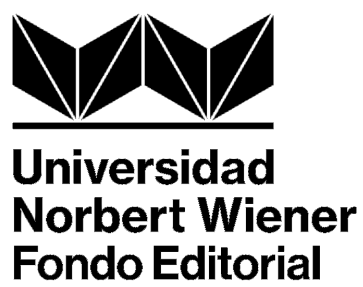




\section{Autores}

Oriana Rivera Lozada de Bonilla (Docente RENACYT Carlos Monge III) Fiorella Inga Berrospi (Docente RENACYT María Rostworowski III) Patrick Albert Palmieri (Docente RENACYT Carlos Monge II) Judith Soledad Yangali Vicente (Docente RENACYT Carlos Monge IV) Michelle Fátima Lozada Urbano (Docente RENACYT María Rostworowski I)

Christian Richard Mejía Álvarez (Docente RENACYT Carlos Monge II) Guido Jean Pierre Bendezu Quispe (Docente RENACYT Carlos Monge II) Hans Lenin Contreras Pulache (Docente RENACYT María Rostworowski I)

\section{Corrección editorial}

Roger A. Pérez García

Asesor técnico

César Antonio Bonilla Asalde (Docente RENACYT Carlos Monge I) 
Primera edición digital, marzo 2021.

C2021, la Universidad Privada Norbert Wiener S.A.

Para el Fondo Editorial de la Universidad Privada Norbert Wiener

Jr. Larrabure y Unanue 110. Urb. Santa Beatriz, Lima. Perú

Contacto: fondoeditorial@uwiener.edu.pe

www . uwiener edu pe

ISSN: 978-612-46707-7-0

Prohibida su total o parcial reproducción por cualquier medio de impresión o digital en forma idéntica, extractada o modificada, en castellano o en cualquier otro idioma sin autorización expresa de la casa editorial. http://doi.org/10.37768/unw.gi.001 


\section{Índice general}

Presentación de la colección _. . . . . . . . . . . . . . . . 10

Presentación del volumen . . . . . . . . . . . . . . . . . . 12

1 Elaboración de Estudio de Factibilidad 15

1.1 Sobre el estudio de factibilidad . . . . . . . . . . . . 15

1.2 Carátula . . . . . . . . . . . . . . . . . . 19

1.3 Introducción . . . . . . . . . . . . . . . 20

1.4 Aspectos Generales . . . . . . . . . . . . . . . 20

1.5 Estudio de mercado . . . . . . . . . . . . . . . 22

1.6 Estudio técnico . . . . . . . . . . . . . . . . . . . 24

1.7 Estudio financiero . . . . . . . . . . . . . 25

1.8 Conclusiones y recomendaciones . . . . . . . . . . 26

1.9 Referencias bibliográficas . . . . . . . . . . . . 26

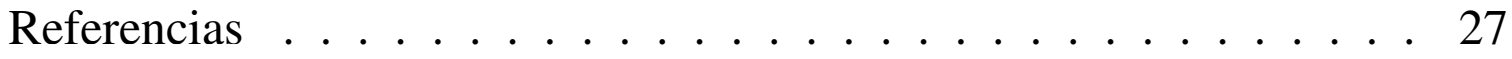

2 Elaboración de Informe de Experiencia Profesional 29

2.1 Sobre el informe de experiencia profesional . . . . . . . . 30

2.2 Carátula . . . . . . . . . . . . . . 33 
2.3 Capítulo I - Antecedentes y Descripción de la experiencia . . . . 34

2.4 Capítulo II - Fundamento del tema elegido . . . . . . . . . . 35

2.5 Capítulo III - Aporte y desarrollo de la experiencia . . . . . . . 36

2.6 Conclusiones . . . . . . . . . . . . . . . . 37

2.7 Recomendaciones . . . . . . . . . . . . . . 37

2.8 Referencias bibliográficas . . . . . . . . . . . . . 38

2.9 Anexos . . . . . . . . . . . . . . . . 39

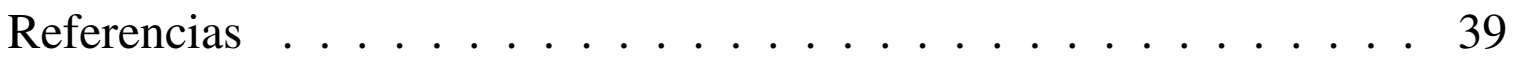

Referencias ................... 40

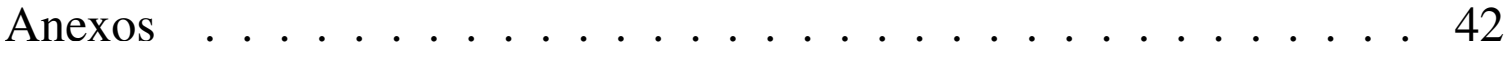

3 Elaboración de Ensayo 43

3.1 Sobre el ensayo . . . . . . . . . . . . . . . . . 43

3.2 Esquema . . . . . . . . . . . . . . . . 48

3.3 Carátula . . . . . . . . . . . . . . . . . . . 49

3.4 Índice . . . . . . . . . . . . . . . . . 50

3.5 Introducción . . . . . . . . . . . . . . 50

3.6 Desarrollo o cuerpo . . . . . . . . . . . . . . 52

3.7 Conclusiones . . . . . . . . . . . . . . . . 54

3.8 Referencias bibliográficas . . . . . . . . . . . . . . 55

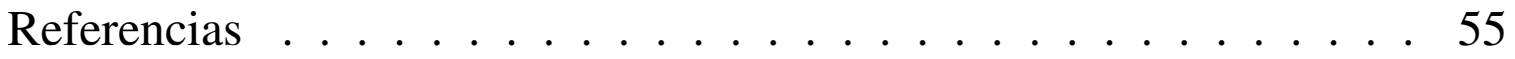

4 Elaboración de un Artículo Científico 57 
4.1 Sobre el artículo científico . . . . . . . . . . . . . . . . 57

4.2 Generalidades antes de escribir . . . . . . . . . . . . . 59

4.3 Preparación del artículo . . . . . . . . . . . . . . 63

4.4 Estructura del trabajo . . . . . . . . . . . . . . . 65

4.5 Short Paper o artículo original breve . . . . . . . . . . 74

Referencias ................... 76

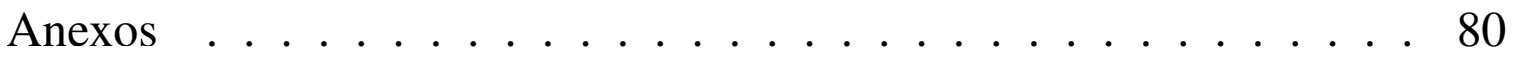

5 Sustentación de Casos $\quad 83$

$5.1 \quad$ Sobre $\operatorname{los}$ casos . . . . . . . . . . . . . . . . . . . . 84

5.2 Carátula . . . . . . . . . . . . . . . . . 91

5.3 Esquema para el estudio de caso clínico . . . . . . . . . . . . 92

5.4 Esquema para el estudio de caso educativo . . . . . . . . . . 102

5.5 Esquema para el estudio de casos administrativos . . . . . . . . 106

5.6 Esquema para el estudio de casos organizacionales . . . . . . . 108

Referencias . . . . . . . . . . . . . . . 112

6 Elaboración de Monografía $\quad 114$

6.1 Sobre la monografía . . . . . . . . . . . . . . . . . . . . 114

6.2 Carátula . . . . . . . . . . . . . . 116

6.3 Índice . . . . . . . . . . . . . . . . . . . 117

6.4 Introducción . . . . . . . . . . . . . . . . . . 117

6.5 Cuerpo o Contenido temático . . . . . . . . . . . . 118

$\begin{array}{ll}\text { Universidad Privada Norbert Wiener } & 7\end{array}$ 
6.6 Pautas para la redacción . . . . . . . . . . . . . . . . . . 118

6.7 Sistematización de la información y ensamble teórico . . . . . 121

6.8 Conclusiones . . . . . . . . . . . . . . . . . . . . . . 122

6.9 Referencias . . . . . . . . . . . . . . . . . . . . 122

6.10 Apéndices . . . . . . . . . . . . . . . . 123

Referencias . . . . . . . . . . . . . . . . . 124

7 Elaboración de Tesina $\quad 127$

7.1 Sobre la tesina . . . . . . . . . . . . . . . . 128

7.2 Carátula . . . . . . . . . . . . . . 133

7.3 Índice . . . . . . . . . . . . . . . . . . . . . . . . 134

7.4 Introducción . . . . . . . . . . . . . . . . . . . 134

7.5 Situación problemática . . . . . . . . . . . . . . . . . 134

7.6 Justificación e importancia de la investigación . . . . . . . . 135

7.7 Formulación de los objetivos o propósitos de la investigación . 135

7.8 Marco teórico o referencial . . . . . . . . . . . . . 135

7.9 Aspectos metodológicos . . . . . . . . . . . . . . . 136

7.10 Resultados . . . . . . . . . . . . . . . . . 136

7.11 Conclusiones . . . . . . . . . . . . . . . . . 136

7.12 Referencias bibliográficas . . . . . . . . . . . . . 137

Referencias . . . . . . . . . . . . . . 137 



\section{Presentación de la colección}

Desde el 2019, el Vicerrectorado de Investigación de la Universidad Privada Norbert Wiener ha trabajado para articular los ejes centrales de la labor universitaria. El reforzamiento de la relación entre docentes, investigadores y alumnos es una preocupación central de este órgano administrativo, puesto que facilita la preparación de nuevos investigadores desde los más tempranos niveles de formación profesional. En ese sentido, se han propiciado espacios de encuentro e intercambio que permitan recopilar las principales dificultades, dudas y desafíos que la comunidad universitaria encuentra al momento de desarrollar sus actividades académicas y de investigación.

La presente colección de textos es producto de estos intercambios, y del trabajo exhaustivo y comprometido de los docentes investigadores adscritos a nuestro vicerrectorado. Cada una de estos volúmenes presenta de forma didáctica los pasos, estrategias y consideraciones de citado y referencia que los estudiantes e investigadores deben tomar en cuenta al momento de redactar sus trabajos, productos y publicaciones. Para ello, se ha realizado un trabajo amplio de revisión bibliográfica con especial énfasis en las tendencias y prácticas correspondientes a todas las carreras y especialidades ofrecidas por nuestra institución.

Esperamos que esta primera versión de nuestras guías de trabajo sea de uso común y se transforme, con el tiempo, en un parámetro conducente 
a buenas prácticas académicas y profesionales. Este es el compromiso de nuestra universidad y de su afán por la mejora continua.

\author{
Roger A. Pérez García \\ Jefe de Fondo Editorial
}




\section{Presentación del presente volumen}

Si la educación y la investigación son responsabilidades centrales de la universidad, entonces la formación en investigación es la síntesis paradigmática de nuestra labor institucional. Esta formación no se limita a futuros especialistas o profesionales que deseen dedicarse a la docencia e investigación, sino que incluye a toda la comunidad universitaria. La investigación es una labor dedicada en la que se desarrollan capacidades intelectuales y creativas que son cruciales para cualquier profesional, dentro y fuera de las instituciones de educación superior. Por ello, es central que esta formación sea acompañada y dirigida desde el inicio por parámetros y lineamientos claros. Estos deben permitir al investigador, profesional o en formación, resolver eficientemente sus dudas y dificultades. Además, dichos parámetros deben ser lo suficientemente flexibles como para adaptarse a la amplia variedad de especialidades, temas y requisitos editoriales y bibliográficos que podamos encontrar. Por ello, el Vicerrectorado de Investigación de la Universidad Privada Norbert Wiener ha considerado necesaria la creación de esta Guía de productos observables de investigación, a fin de facilitar la labor de docentes y estudiantes.

En el presente volumen el lector encontrará todas las instrucciones, detalles, métodos y estrategias necesarias para llevar a cabo exitosamente cualquier investigación que el estudiante deba realizar en su camino a la obten- 
ción del grado de bachiller. Este tiempo formativo es crucial, pues la experiencia positiva o negativa del estudiante en sus investigaciones iniciales puede acercarlo o alejarlo de un campo de acción profesional que cada vez recibe mayor demanda. Al mismo tiempo, esta guía es un parámetro claro a través del cual el docente puede evaluar el desempeño de sus estudiantes. Así, al poner esta obra a disposición de la comunidad universitaria, facilitamos nuestra labor académica y promovemos el desarrollo profesional de nuestros estudiantes.

Esta guía se propone ser un parámetro en constante mejora y renovación. Si la curiosidad es un atributo propio de la labor investigativa, entonces no es de extrañar que los lineamientos, procesos y demandas metodológicas en investigación se encuentren en constante revisión y actualización. En ese sentido, la curiosidad y creatividad de los investigadores generan cambios y mejoras en la manera como realizamos nuestros trabajos de investigación. Por ello, esta guía es solo el inicio, una introducción y una invitación al vasto campo de la producción científica.

Oriana Rivera Lozada de Bonilla Vicerrectora de Investigación (e) 



\section{Elaboración de Estudio de}

\section{Factibilidad}

En el presente capítulo, se ha recopilado información para facilitar a los alumnos la elaboración de un estudio de factibilidad. Los aportes son básicos y claros, para acompañarlos en el planeamiento del estudio y la redacción del mismo. Asimismo, esperamos que estos datos sean parte del aprendizaje necesario para futuros profesionales y del logro de habilidades para elaborar este tipo de estudios. Mostramos aquí cómo abordar los aspectos generales relacionados a la empresa, y el estudio de mercado para llegar al estudio técnico y financiero que permite las conclusiones y recomendaciones.

\subsection{Sobre el estudio de factibilidad}

Factibilidad se refiere a la disposición de los recursos que se necesitan para cumplir metas o proyectos. También se define como el grado de posibilidades con que se cuenta para lograr un proyecto. Los estudios de factibilidad son estudios definitivos de mercado, donde se recopila información clave sobre el desarrollo de un proyecto. Basado en ello, se decide si el estudio se desarrolla y se implementa. 
Este tipo de estudios proveen información para comprender si el nuevo producto es acorde con los requisitos de la demanda en este ambiente cambiante, ya que analiza las características de las personas y sus necesidades, así como las características de los productos, del lado de la oferta. Por otro lado, si la idea no fuera fácil de ponerla en práctica, esta puede ser descartada sin generar daño alguno, debido a no se debe haber generado un grueso de inversión.

Dada las nuevas tendencias en el mundo, este tipo de estudios permite saber los perfiles de los consumidores y cumplir con sus requerimientos. Además, permite conocer qué condiciona al nuevo producto y cuáles podrían ser sus valores agregados. Durante la elaboración de un estudio de factibilidad es posible incorporar una estructura acorde a la naturaleza y alcance del proyecto que se encuentre desarrollando.

\subsubsection{Esquema}

Carátula

Introducción

1. Resumen

2. Aspectos Generales

I. Situación actual de la empresa responsable del proyecto 
II. Satisfacción y necesidades

III. Objetivos

IV. Servicios y/o productos

V. Justificación y valor

3. Estudio de Mercado

I. Situación del sector a través de la competitividad del mercado

II. La Demanda

III. La oferta

IV. Precio del producto

4. Estudio Técnico

I. Capacidad de la Empresa

II. Programa de producción y ventas

III. Procesos y Tecnología

IV. Insumos requeridos

V. Requerimiento de personal y costo

VI. Organización

5. Estudio Financiero 
I. Necesidades totales de Capital

II. Índices de evaluación del proyecto

III. Cronograma de ejecución

IV. Aspectos legales que favorecen o limitan el proceso

V. Aspectos ambientales

VI. Aspectos de higiene y seguridad industrial

6. Conclusiones y recomendaciones

7. Referencias Bibliográficas 


\subsection{Carátula}

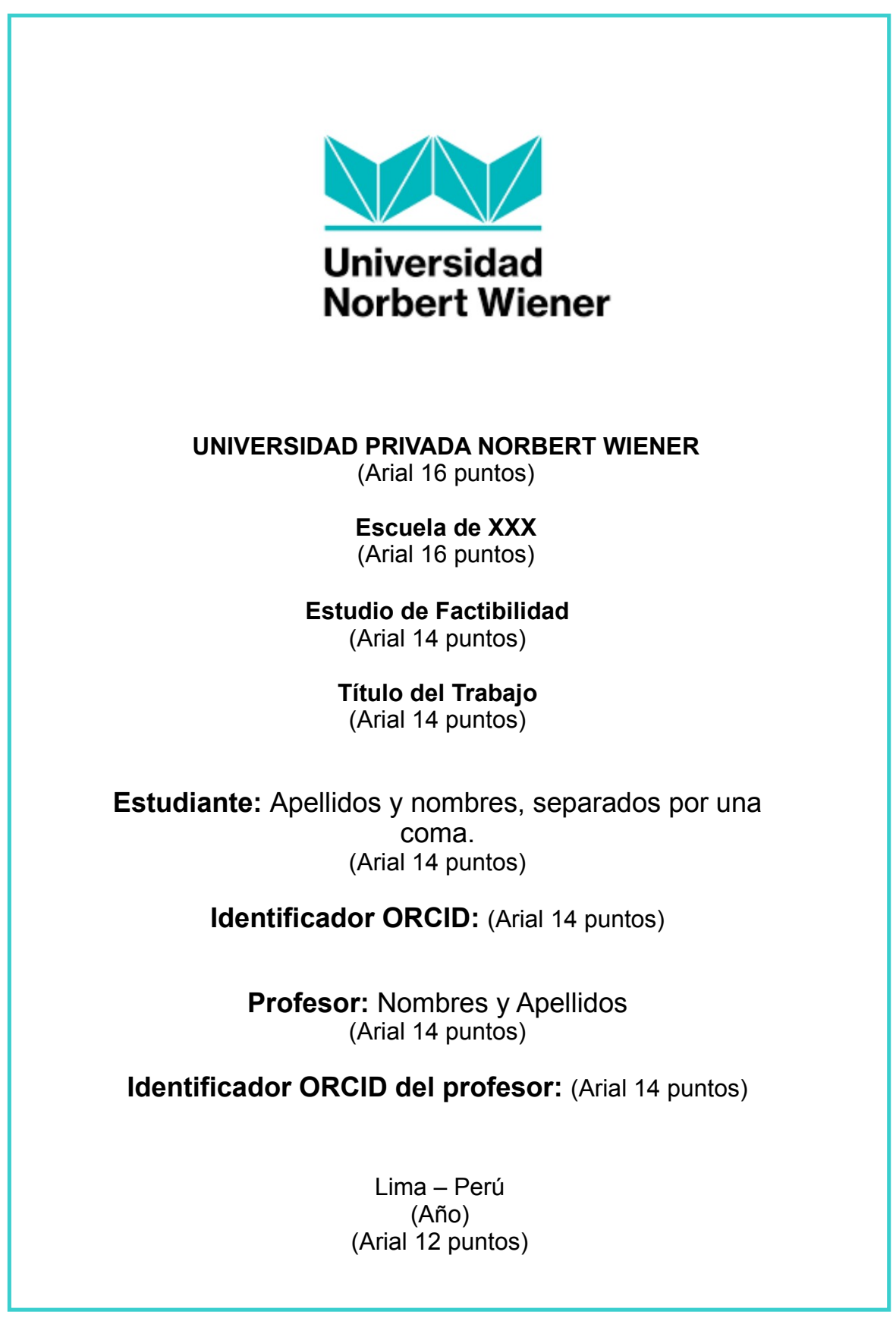




\subsection{Introducción}

Esta parte también se conoce como perfil del proyecto, y describe el contenido del informe. Se narra de manera clara y breve cuál es la idea del proyecto. La prefactibilidad considera múltiples variables y se incluye una reflexión sobre la idea base del estudio, para darle pase al estudio de factibilidad.

En esta parte, se explica las partes que tiene el proyecto. Luego, como en todos los trabajos se incluye un resumen en el que se ofrece información suficiente con precisión para tomar la mejor decisión. Debe ser puntual e indicar todo el resumen del estudio de forma sucinta, e indicar las partes que se desarrollarán.

\subsection{Aspectos Generales}

Los aspectos generales describan la manera en que está posicionada la empresa y cuál es su situación actual, la satisfacción y necesidades de la misma, los objetivos trazados, los servicios y productos, y la justificación y valor.

La descripción de la situación actual de la empresa responsable del proyecto debe incluir su situación y que la caracteriza, cuáles son el rubro o los rubros a los que se dedica. También debe hacer hacer énfasis en el área donde el sujeto se desempeña. 
La información sobre los responsables y/o quien promueve el estudio debe incluir datos como la razón social, la figura jurídica, entre otros, y por quién está representada la empresa. Aquí también se puede colocar a cargo de quién está, y a quién se debe rendir la información, según las actividades que realiza.

Los aspectos económicos de la empresa describen ciertas políticas que puedan limitar el proyecto. Es necesario saber cuáles son e identificar las necesidades expresadas en los aspectos técnicos, legales o económicos. Como parte de las políticas de la empresa, no es posible mencionar ciertos puntos que deben mantenerse en total resguardo. Se debe saber cuáles son y no incurrir en ese hecho.

Como se encuentra la estructura de la organización, esto incluye su ubicación. Aquí debe incluir el organigrama de la institución o empresa y el manual de organización y funciones. Es así que el aspecto de satisfacción y necesidades identifica la empresa, forma parte de su definición y su importancia dentro del entorno. Esto se traduce en cuál es la oportunidad de la empresa y las razones por las que existe, y en evaluar la duración de esa oportunidad.

Los objetivos intentan mostrar si los recursos de la empresa disponibles ayudarán a definir la utilidad del proyecto. Se determina la viabilidad económica, financiera, ambiental, técnica y de mercado. Debe estar explícito el alcance del estudio y la intención fundamentada en cuáles son los pro- 
blemas que existen o las necesidades que deben ser satisfechas. Otro aspecto son los servicios y/o productos. Estos son lo primero que debe ser identificado. En esta sección se empieza por identificar el producto y describir algunas características como las especificaciones técnicas, la durabilidad, o si existen productos similares o complementarios. Se describe si el punto de inicio o nacimiento de un nuevo producto responde a las necesidades de la población, puede complementar si se encuentran solos o están inmersos en grandes proyectos; es necesario considerar el aspecto legal.

La justificación y valor enfocan la naturaleza del proyecto: por qué es importante y cuán posible es generar bienes y servicios que sean requeridos en el mercado.

\subsection{Estudio de mercado}

Se refiere a quién se dirige el producto (puede ser un segmento del mercado). Incluye el despliegue de estrategias de mercadeo y describe la base financiera con la que cuenta la empresa y la evaluación. La situación del sector y la competitividad son factores que determinan los retos a los que se enfrenta la empresa y en los que se basará el desarrollo de la estrategia basada en el cambio.

Evaluar a los clientes corresponde identificar quienés son y dónde se ubican los posibles compradores. Aquí es recomendable incluir estrategias 
de llegada al consumidor, alguna propuesta para negociar el producto, mejores precios, mejor calidad, y cambio de proveedor. En ese sentido se valora la competencia actual y el potencial futuro, y se describe cómo son los actuales competidores, sus intenciones, sus objetivos, sus estrategias, y cuáles son sus fortalezas para dar satisfacción a parte del mercado. Esto es vital para alcanzar un mejor desempeño que las empresas existentes en el mercado. También se define quiénes serán los proveedores que mantengan la calidad de productos y la entrega oportuna. Un factor importante que se debe mantener en todo momento es conocer los productos sustitutos, y cuáles ejercen presión al establecer rangos de precios a los productos similares.

El mercado se define por la oferta y la demanda. La demanda se refiere al consumidor y cómo se le caracteriza en el comportamiento de la población, no solo actual sino también futuro. Además, responde a cuáles serán los factores que condicionarán la demanda actual y futura. Se debe lograr establecer cuáles serán las estrategias para lograr el mercadeo. Mientras, la oferta se refiere a quiénes ofrecen el producto, también conocido como oferentes. Incluye cómo estos se distribuyen y cuál es su tipología, cómo se describe su comportamiento actual, su volumen de importaciones y los factores que determinan y condicionan la oferta actual y futura. En cuanto a los oferentes, se describe la capacidad instalada y ociosa, planes de ampliación y otros proyectos a iniciar. Los precios se muestran en series de tiempo. Se analiza y evalúa los datos y el proceso de comercialización. 


\subsection{Estudio técnico}

El estudio técnico analiza y propone diferentes alternativas de proyecto para llegar a producir el bien que se quiere alcanzar (funcionalidad y operatividad). Incluye tamaño, ubicación, tipo de procesos, insumos y, costos del área productiva para el bien que se trabajará.

La capacidad de la empresa debe describir todos aquellos factores que estarían condicionando el tamaño de la misma: la capacidad instalada, la capacidad a instalarse y la capacidad usada. Así mismo, se debe incluir un programa de producción y ventas, que incluya un esquema de estrategia comercial y cómo los recursos son utilizados para mejorar la producción. Entre ellos, se encuentran los materiales para la elaboración (materia prima), mano de obra, aspectos de logística u otros, que son manejados según el tiempo programado junto a un calendario de actividades.

Otra área es la de procesos y tecnología. Esta describe el proceso productivo (flujograma del proceso). Aquí se listan las maquinarias, equipos, herramientas e instalaciones o áreas necesarias. Se debe identificar el plan de requerimientos de insumos, cuál es la disponibilidad de los insumos, su origen, precios, y si existen sustitutivos y desperdicios.

Después de valorar la capacidad de la empresa, se define el tipo de personal que se requiere, se describe si se evalúa la oferta y demanda de mano de obra, tipo de personal, y las necesidades de capacitación. Todos los datos 
mencionados en conjunto permiten organizar las necesidades de la empresa.

\subsection{Estudio financiero}

El estudio financiero compara beneficios y costos. Finalmente, determina si es conveniente desarrollar el proyecto o no. Aquí debe anotarse las necesidades totales de capital. Esto se establece a través del requerimiento total, tanto de activos fijos tangibles e intangibles. Debe incluirse el capital de trabajo, los procesos y fuentes de financiamiento, si existen condiciones de crédito, así como otros gastos de fabricación y ventas. Aquí se puede definir cómo se han estructurado los costos, y dentro de esto, aquellos con financiamiento. También puede abarcar montos de las ganancias y las pérdidas con financiamiento, flujo de caja, ingresos anuales, y capacidad de pago.

Los índices de evaluación del proyecto son los valores siguientes: el valor actual neto (VAN), la tasa interna de retorno (TIR), período de recuperación del capital (PRC), relación beneficio-costo (RBC), inversión por empleo, punto de equilibrio (PE) y costos unitarios. Todos estos valores también son conocidos como índices de rentabilidad y determinan si el proyecto vale la pena realizarlo o no. Las inversiones y el financiamiento establecen tiempos a cumplir y capitalizar activos contablemente. También debe establecerse si existen aspectos legales que favorezcan o limiten el proceso, se debe conocer el marco legal y otras leyes, como pautas técnicas para los 
productos, para saber si existe un manual de advertencias y protección legal en el ámbito de patentes.

Los aspectos de protección del medio ambiente son un criterio primordial en muchos proyectos; se crean indicadores en muchos casos para medir este aspecto. Finalmente, los aspectos de higiene y seguridad industrial son requisito necesario para medir la calidad de los productos que se elaboren.

\subsection{Conclusiones y recomendaciones}

Las conclusiones y recomendaciones deben estar separadas por aspectos sociales, aspectos técnicos y aspectos económico-financieros. Las conclusiones nos dirán si es conveniente hacer o no el proyecto, o si es necesario investigar más. Se recomienda que estén documentadas o basadas en alternativas que demuestren que es posible llevarse a cabo el proyecto.

\subsection{Referencias bibliográficas}

Se debe incluir las referencias para lograr darle el marco científico al estudio, según sean utilizadas dentro del texto. El sistema de citado a usar dependerá del trabajo, de la especialidad y de las indicaciones del asesor o docente a cargo. Los sistemas más usuales son los acuerdos de American Psychological Association (APA) y el sistema Vancouver. Se sugiere revisar los respectivos manuales de la universidad. 


\section{Referencias}

Mendez Alvarez, C. E. (2020). Metodología de la investigación: Diseño y desarrollo del proceso de investigación en ciencias empresariales. (5 ed.) Alfaomega Colombiana S.A.

Martínez, J.M. y Prieto, A.F. (2016). Guía metodológica para la elaboración de un estudio de factibilidad. Estudio de caso: Fabricación y venta de barras de cereal.

Fiscal Escalante R. Metodología de análisis para estudios de factibilidad técnica-económica en sistemas de generación eléctrica costa fuera. Tendencias tecnológicas. Boletín IIE, (Jul-Sep. 2007); p. 92 - 97.

Harvey, L. A. (2018). Feasibility and pilot studies pave the way for definitive trials. Spinal Cord, 56(8), 723-724. https://doi.org/10.1038/s41393-0180184-X

Hernández M. Guía Proyecto: Factibilidad. Universidad Industrial de Santander. Instituto de proyección regional y educación a distanca (IPRED). Gestión empresarial.

KASAI Takashi (2007). Formulación de un proyecto y análisis de factibilidad. Buenos Aires: Secretaría de ambiente y desarrollo sustentable. 
Ministerio de transporte e infraestructura, división general de planificación. Manual para la elaboración de estudios de pre-factibilidad y factibilidad. Nicaragua, Corea y Asociados S.A. 2008. 152 p.

Story, D. A., Leslie, K., y French, C. (2018). Feasibility and Pilot Studies: Small Steps before Giant Leaps. Anaesthesia and Intensive Care, 46(1), 11-12. https://doi.org/10.1177/0310057x1804600103

Tickle-Degnen, L. (2013). Nuts and Bolts of Conducting Feasibility Studies. American Journal of Occupational Therapy, 67(2), 171-176. https://doi.org/ 10.5014/ajot.2013.006270 


\section{Elaboración de Informe de}

\section{Experiencia Profesional}

Para muchos estudiantes, lograr el título profesional culmina con la entrega de la tesis. Otra opción para titularse es que el bachiller demuestre a través de un documento que ha alcanzado las competencias profesionales entregadas a lo largo de las clases universitarias. Es así que la titulación por experiencia profesional está conformada por la experiencia de una actividad profesional. Esta podrá ser sustentada públicamente ante un jurado evaluador, donde se pregunta al expositor aspectos relacionados al informe, seguido de un balotario de preguntas relacionadas a las asignaturas llevada en la carrera. Esta modalidad solo se aplica únicamente a la obtención del título profesional.

Como muchos informes o trabajos, este documento debe cumplir con los requisitos académicos establecidos en cada universidad. este capítulo constituye una guía que facilita a los estudiantes la elaboración de un Informe de experiencia profesional. Se incluyen aquí los lineamientos establecidos por el Vicerrectorado de Investigación y que deberán ser tomados en cuenta en la presentación del respectivo informe. Además, se describe su esquema general y se bridan pautas a seguir en cada una de sus partes. 


\subsection{Sobre el informe de experiencia profesional}

El informe sobre experiencia profesional es un documento que explica y describe una reflexión personal sobre un tema específico y puede considerar la experiencia obtenida incluso antes de la obtención del grado de bachiller. Este informe puede abarcar las prácticas que han desarrollado estudiantes en una empresa o en un área específica dentro el área profesional al que pertenece. En este se detallan las actividades, puede ser de forma anual o por el periodo desarrollado. El estudiante debe mostrar de forma transparente todas las actividades a favor o no con las que tuvo que lidiar durante este periodo.

\subsubsection{Esquema}

El informe de experiencia profesional debe incluir en la portada el logo de la universidad Norbert Wiener, y los datos personales y los datos del estudio. Adicionalmente, debe incluir el nombre del profesor o profesores por quien(es) fue monitoreado durante este proceso. El título siempre refleja lo que contiene el documento. Puede incluir una dedicatoria si lo considera necesario.

Como en muchos trabajos, el informe profesional cuenta con un resumen. Este debe ser breve, no mayor a doscientas (200) palabras. Contiene las partes de un resumen estructurado: breve introducción donde se con- 
textualiza el tema; los objetivos del informe, que derivan de las actividades realizadas, el lugar donde se desarrolló la práctica, seguido de las actividades desarrolladas y las conclusiones a las que llegó. Se usa un lenguaje claro y conciso.

Debe incluir un índice, según el esquema del informe. Se puede incluir algunos aspectos relevantes para entender las actividades que ha desarrollado.

Después del índice viene la Introducción. Esta trata de conducir al lector a los aspectos que se van a tratar en el documento. Se incluye el lugar donde se desarrolló la pasantía o práctica, información sobre las actividades desarrolladas y los aspectos metodológicos usados. Datos como la forma de realizar la distribución y el puesto designado deben ser mencionados. Se debe colocar los capítulos abordados, y finalmente, la conclusión final del trabajo.

Se muestra a continuación el esquema general a seguir:

\section{Carátula}

Título

Dedicatoria

Resumen

Índice General 
1. Introducción

2. Capítulo I. Antecedentes y Descripción de la experiencia

I. Antecedentes

II. Descripción general de la experiencia

3. Capítulo II. Fundamento del tema elegido

4. Capítulo III. Aporte y desarrollo de la experiencia

5. Conclusiones

6. Recomendaciones

7. Referencias Bibliográficas

Anexos 


\subsection{Carátula}

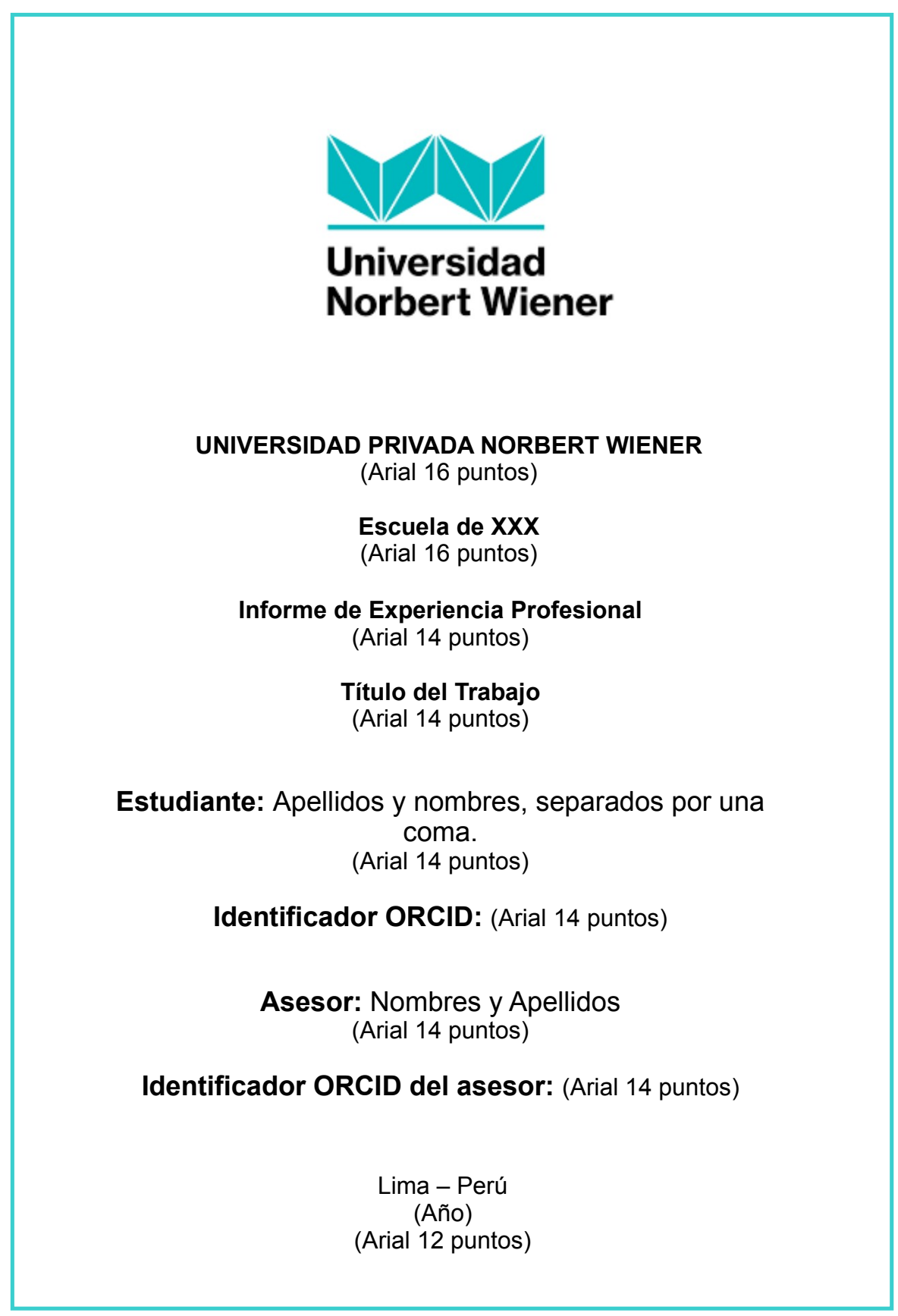




\subsection{Capítulo I - Antecedentes y Descripción de la experiencia}

En esta sección, se debe explicar los aspectos generales que están unidos al tema de trabajo, se debe hacer una descripción de la empresa o institución, cuáles han sido los antecedentes de la misma, y se hace una descripción general de la experiencia. Adicionalmente, se debe indicar el tema.

a) Describir a la empresa. Debe incluir una breve reseña desde sus orígenes y sus principales actividades. Mencionar aspectos como: visión, misión, y el contexto en el que se desenvuelve, describir cuáles son los rubros de la organización, y cuáles son los servicios que desarrolla. Se debe especificar cómo está organizada el área o áreas específicas de la empresa donde se ubica el desarrollo de las actividades del estudiante o egresado. Además, realizar una descripción del área física y del personal, e indicar el contexto socioeconómico, ubicación de las instalaciones y sedes, recursos, entre otros.

b) Los antecedentes deben mencionarse siempre que sea posible. Se debe destacar el ámbito en el que se desarrolla su actividad. Explicar cuáles son las referencias que están disponibles, tales como informes desarrollados por otros estudiantes o informes elaborados por trabajadores de otras organizaciones en relación al área donde trabajó.

c) La descripción general de la experiencia. Debe dar una explicación 
del cargo de su jefe inmediato y de sus funciones. Se debe indicar el propósito del puesto, los objetivos y sobre todo como se incluyeron sus actividades. Aquí también se pueden mencionar las actividades y los retos que le fueron asignados. Además, puede identificar los productos o procesos que se establecerán en el informe, estos se describen como actividad principal o como otras actividades. Finalmente, puede incluir los resultados concretos que son pretendidos durante la actividad programada.

\subsection{Capítulo II - Fundamento del tema elegido}

En este capítulo se debe explicar el fundamento sobre el tema elegido y que va acorde a los objetivos de este trabajo. Debe también desarrollar un marco basado en estudios pasados, información bibliográfica e información de la propia empresa. Asimismo, debe sustentar cómo se enlazan los aspectos teóricos y la práctica, y la manera como han permitido alcanzar el desempeño profesional en la situación real de la empresa (puede describir aspectos puntuales). Se debe desarrollar una descripción de las actividades a su cargo, la metodología o los procesos usados en ellas, ya sea horarios, rotación y si otras personas ayudaron en este proceso. Para esto, puede detallar las corrientes o teorías que rigen las diversas actividades, y si aplicó métodos de análisis, como el cualitativo, cuantitativo, correlacional u otros. 
No dejar de lado la información sobre otros aspectos, como sistemas informáticos y de comunicación que son aplicados en la institución, sus características, y cómo han permitido alcanzar sus objetivos. Finalmente, debe indicar cómo se valoró su desempeño, y debe mencionar cuáles fueron las variables, parámetros o indicadores que fueron utilizados para medirlo (si existieron).

\subsection{Capítulo III - Aporte y desarrollo de la experiencia}

En este capítulo, se menciona el desarrollo de la experiencia. Debe explicar las actividades programadas del día a día y cómo mejoraron sus conocimientos. Se debe continuar con la estrategia y metodología empleada durante el desarrollo de las actividades; aquí el estudiante o egresado debe aplicar criterios para ordenar esta sección, ya sea en orden cronológico por las áreas en las que rotó, o por las tareas asignadas, entre otros. Describir cada una de las actividades realizadas para tratar de crear una reconstrucción en el tiempo de las mismas, que permita una mirada en conjunto de lo que significó toda la experiencia. Puede aquí crear una figura ubicando las actividades y cuál fue su desenvolvimiento. Es necesario también mencionar los problemas o retos a los que se tuvo que enfrentar, como se encontró la solución y, de ser el caso, quien o quienes brindaron ayuda. No olvidar ubicar estos aspectos en el marco teórico y la metodología aplicada en este 
capítulo.

\subsection{Conclusiones}

Las conclusiones son la respuesta a los problemas y estas pueden estar ordenadas en tres niveles: teóricas, metodológicas y técnicas. Debe especificar los nuevos conocimientos que se obtuvieron con la experiencia profesional desarrollada, desde una mirada crítica. Describir su apreciación, tanto respecto a los conocimientos, como a su desenvolvimiento en la práctica. Las conclusiones deben estar numeradas y contar con un orden según los capítulos y según sus objetivos. Es importante hacer la valoración crítica de la manera en que fueron organizadas sus labores, cuáles fueron sus retos, y los problemas presentados durante este periodo. Se debe describir estos puntos por la importancia dentro de sus objetivos.

\subsection{Recomendaciones}

Las recomendaciones se deben encontrar ordenadas según las conclusiones mencionadas. Se debe considerar las decisiones relevantes que se tomaron. En esta sección se recomienda organizar cuáles fueron las soluciones a los retos, o cuál podría ser la solución a seguir, así como justificar los objetivos que no se lograron y describir posibles soluciones. Explicar sus razones desde la perspectiva de la empresa, desde el aspecto personal o social y des- 
de el aspecto académico. Además, realizar propuestas que permitan mejorar aspectos poco desarrollados o que obstaculizan el cumplimiento de aspectos específicos de la experiencia profesional (propias y para la empresa).

\subsection{Referencias bibliográficas}

El sistema de citado a usar dependerá del trabajo, de la especialidad y de las indicaciones del asesor o docente a cargo. Los sistemas más usuales son los acuerdos de American Psychological Association (APA) y el sistema Vancouver. Se sugiere revisar los respectivos manuales de la universidad. 


\subsection{Anexos}

Si los hubiera, se pueden incluir algunos documentos probatorios que ayuden al lector a entender el desarrollo de este informe. Por ejemplo:

- Un glosario

- Organigrama de la empresa u organigrama del área donde trabajó

- Paquetes estadísticos, si fueron usados

- Fotos o figuras de actividades realizadas

- Diagramas

- Cuestionarios e instrucciones de aplicación

- Cálculos y datos como población y muestra con la que trabajó

- Materiales que fueron necesarios

- Listado de costos

- Manuales o fichas técnicas 


\section{Referencias}

Barrientos García, L. . (2020). Esquema del sistema general de riesgos profesionales. Revista De La Facultad De Derecho Y Ciencias Políticas, (97), 134-155. Recuperado a partir de https://revistas.upb.edu.co/index.php/dere cho/article/view/4308

Instituto Nacional de Salud. Breve guía de estilo para la redacción científca. Ministerio de Salud, 2007.

Izurieta G, Negrete F. Informe Profesional. Diss. Escuela Superior Politécnica del Litoral, 2015.

Larrañaga O, Cabezas G, Dussaillant F. Informe completo del estudio de la educación técnico profesional. Chile: PNUD/Área de Reducción de la Pobreza y la Desigualdad, 2013.

López C, Alfonso I, Armenteros I. Redacción y edición de documentos. La Habana: Editorial Ciencias Médicas; 2011.

Portugal Bernedo F. La sistematización de la experiencia profesional como una modalidad de la investigación. El informe profesional para obtener la titulación. Escritura y pensamiento. Año II, N-6, 2000, PP. 95-103.

Servicio Nacional de Sanidad y Calidad Agroalimentaria. Manuales de consulta del SENACE: Normas ortográficas y gramaticales. Argentina: Edicio- 
nes SENASA; 2008.

Superintendencia Nacional de Educación Superior Universitaria. Ministerio de Educación. Reglamento del Registro Nacional de Trabajos Conducentes a Grados y Títulos- RENATI. Dic 2019. Disponible en: https://www.gob.pe/ institucion/sunedu/informes-publicaciones/991491-reglamento-del-registronacional-de-trabajos-conducentes-a-grados-y-titulos-renati

Terigi F. Carrera docente y políticas de desarrollo profesional. Veláz de Medrano, C. y Vaillant, D. (comp), Aprendizaje y desarrollo profesional docente. 2009: 89-99. 


\section{Anexos}

- Reglamento del Registro Nacional de Trabajos de Investigación para optar grados académicos y títulos profesionales - RENATI

4.16 Trabajo de suficiencia profesional: es una modalidad de titulación que implica que el bachiller está en la capacidad de demostrar y documentar el dominio y la aplicación de competencias profesionales adquiridas a lo largo de la carrera. La universidad, institución o escuela de educación superior determinará el plazo mínimo de trabajo en temas de su especialidad, debidamente acreditado mediante un certificado, además de la presentación de un informe que da cuenta de la experiencia preprofesional. Así, podrá ser sustentado públicamente ante un jurado evaluador, en el que se formulan preguntas vinculadas con el informe y un balotario de preguntas de los cursos llevados durante la realización de la carrera, (ver el Anexo $\mathrm{N}^{\circ}$ 1). En el marco de la Ley Universitaria es una modalidad que se aplica únicamente para la obtención del título profesional, el cual también puede ser obtenido a través de la presentación de una tesis. 


\section{Elaboración de Ensayo}

El presente capítulo orientará al estudiante universitario en la redacción de un ensayo académico. Es necesario que el estudiante reflexione y entregue una opinión bien fundamentada, y que aborde temas olvidados o poco claros, de manera que alcance una posición sobre el mismo y defina la problemática y soluciones.

Los contenidos aquí presentados son claros, fáciles de manejar y pueden ser manejados por estudiantes de todas las áreas y ser incluído en cualquiera de los cursos que requieran este tipo de trabajo. Este ejercicio es un paso previo a la escritura del proyecto o de la tesis, de un artículo o de un trabajo de investigación más amplio. En esta guía, explicamos paso a paso como son las partes del ensayo, la introducción, el cuerpo o desarrollo y una conclusión.

\subsection{Sobre el ensayo}

El ensayo es definido como una forma de escritura donde el autor argumenta y reflexiona sobre cualquier tema específico. Se le considera un género literario que está inmerso dentro del género didáctico. Otra visión desde el ámbito académico le da la definición de un género, cuyo rasgo notable es la exhibición lógica del pensamiento (Anguiano et al, 2014). Autores como 
Montaigne o Cuesta describen que quienes escriben un ensayo deben poner a prueba muchas habilidades de su intelecto, como el análisis y debate de sus ideas, y demostrar y justificar su posición en el ensayo (Montaigne, 2006).

La investigación es tarea de todos los estudiantes. Este tipo de ensayo es una pauta para quienes incluso con poca experiencia podrían elaborar un trabajo que implique investigación documental. El ensayo explora a través de documentos científicos cosas reales que le permiten acercarse a la verdad, asimismo, debe tener un gran valor y practicado frecuentemente para que los alumnos expresen opiniones fundamentadas.

La extensión del documento va entre cinco y diez páginas, y debe tener una escritura clara y transparente. Empieza con un planteamiento o propósito el desarrollo a favor y/o en contra, así como la síntesis o conclusión. Las relaciones que deben existir en el texto (semánticas) van desde los más amplio a lo más pequeño, de lo particular a lo general, comparar o contrastar, causa-efecto y problema o solución (Arenas, 1997).

Los temas deben ser del interés del que lo escriba, y de ninguna manera impuestos. Es necesario una revisión exhaustiva de la información general, o contactarse con expertos en el tema. 


\subsubsection{Definición de ensayo}

El ensayo es conocido como un escrito académico donde el tema escogido es evaluado y se emite una conclusión. El término ensayo también se refiere a una forma común de escribir en el ámbito académico para dar a conocer un tema general o darles sustento a ideas propias. Otra noción planteada por Arenas Cruz es que el ensayo es un texto argumentativo, autónomo, dirigidos a la reflexión humanística y exploración de temas reales (Arenas, 1997).

En ese sentido, el ensayo utiliza lo que tiene forma, ordena cosas, $\mathrm{y}$ manifiesta la verdad; es necesario que sea claro, y debe responder a una pregunta. El contenido debe ser relevante, estar organizado y usar correctamente el lenguaje. Esta interacción discursiva produce, transmite y evalúa el conocimiento, dentro de esta forma existen formas específicas y particulares según las áreas o disciplinas que se aborden, y el propósito del trabajo. Así, se define el ensayo académico que es un medio donde se reflexiona, esto requiere habilidades dirigidas al pensamiento y modelos de escritura de tipo académica que argumenten y sustenten.

Como cualquier trabajo, se encuentra bien fundamentado por una correcta búsqueda de información, en bases científicas, que le darán mayor validez. Se espera que quien escribe adopte una postura en relación a un tema y debe lograr influenciar en los lectores. 


\subsubsection{Tipos de ensayos académicos}

Quien escribe un ensayo puede tener diferentes propósitos, es así como los ensayos académicos pueden ser expositivos, argumentativos y analíticos.

- Ensayo expositivo: en este caso el texto describe y clasifica un tema a los lectores.

- Ensayo argumentativo: genera una postura crítica relacionada a un tema y defiende por medio de razonamientos basados en evidencia.

- Ensayo analítico: relaciona elementos de un evento, los valora y analiza las consecuencias. 
La siguiente tabla muestra las características de los tres tipos de ensayos académicos:

\section{Tabla 1:}

Tipos de ensayo

\begin{tabular}{|c|c|c|c|}
\hline Partes del ensayo & Ensayo expositivo & Ensayo argumentativo & Ensayo analítico \\
\hline $\begin{array}{l}\text { Introducción } \\
\text { (exordio) }\end{array}$ & $\begin{array}{l}\text { Ofrece el plantea- } \\
\text { miento del tema de } \\
\text { forma general. }\end{array}$ & $\begin{array}{l}\text { Ofrece el planteamien- } \\
\text { to del tema de forma } \\
\text { general. }\end{array}$ & $\begin{array}{l}\text { Presenta el tema de for- } \\
\text { ma general, delimita las } \\
\text { partes que lo compo- } \\
\text { nen, incluye la o las } \\
\text { perspectivas que rigen } \\
\text { el ensayo. }\end{array}$ \\
\hline $\begin{array}{l}\text { Cuerpo o desa- } \\
\text { rrollo (argumen- } \\
\text { tación) }\end{array}$ & $\begin{array}{l}\text { Define, y describe } \\
\text { cada una de las ideas } \\
\text { implicadas en la te- } \\
\text { sis. }\end{array}$ & $\begin{array}{l}\text { Utiliza argumentos y } \\
\text { evidencias. }\end{array}$ & $\begin{array}{l}\text { Establece relación entre } \\
\text { las partes. }\end{array}$ \\
\hline $\begin{array}{l}\text { Conclusión } \\
\text { (epílogo) }\end{array}$ & $\begin{array}{l}\text { Organiza las ideas } \\
\text { que trabajó en el } \\
\text { desarrollo, utiliza la } \\
\text { evidencia y expresa } \\
\text { las implicancias. }\end{array}$ & $\begin{array}{l}\text { Sintetiza los argumen- } \\
\text { tos y utiliza la eviden- } \\
\text { cia. }\end{array}$ & $\begin{array}{l}\text { El resultado del análisis } \\
\text { es evaluado, explica las } \\
\text { implicancias. }\end{array}$ \\
\hline $\begin{array}{l}\text { Lista de referen- } \\
\text { cias }\end{array}$ & Fuentes utilizadas. & Fuentes utilizadas. & Fuentes utilizadas. \\
\hline
\end{tabular}




\subsection{Esquema}

1. Carátula

2. Índice

3. Introducción

4. Desarrollo o cuerpo

5. Conclusiones

6. Referencias 


\subsection{Carátula}

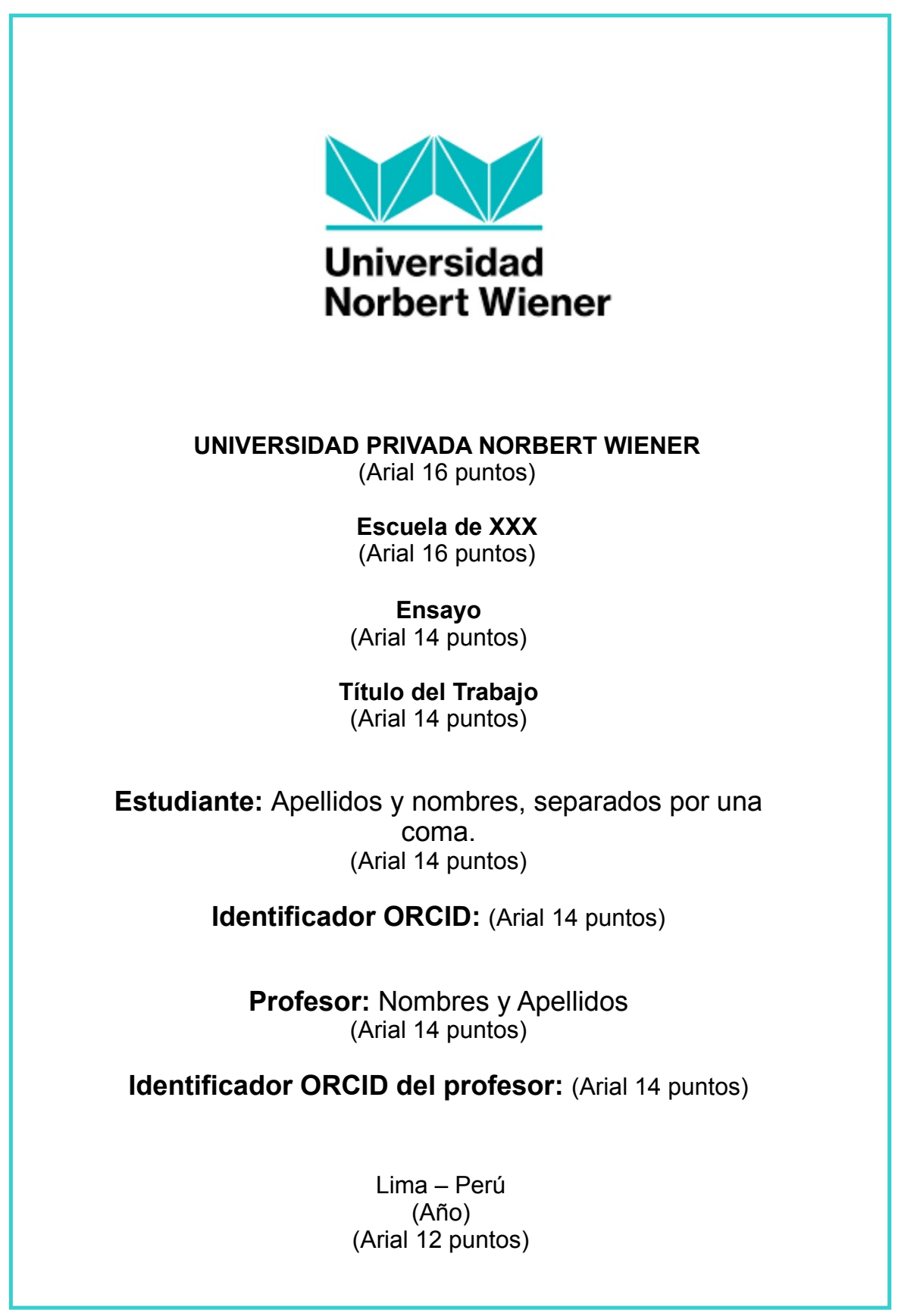




\section{4. Índice}

Se desarrolla según el esquema de trabajo. La estructura formal y característica del ensayo incluye la introducción, el desarrollo o argumentación y conclusión. Al ser este un ensayo académico, se considera las referencias bibliográficas al final.

\subsection{Introducción}

Aquí se describe cuál es el propósito del ensayo, o planteamiento general del tema de manera que se introduce al lector en el tema que se tratará y se establece el marco relevante al ensayo. En esta introducción, se puede describir el contenido del ensayo. Después de delimitar y dar un enfoque, se puede generar ideas.

Delimitar el tema a tratar se refiere a decir dónde inicia el trabajo y hasta dónde llegamos y tener un punto clave para desarrollar las búsquedas. De un tema amplio y general se pasa a un área particular y va delimitando paso a paso hasta conseguir un punto específico. El tema se desarrolla a través de oraciones temáticas de los párrafos que conforman y argumentan el ensayo.

Después de delimitar el tema, se recomienda que se realice una búsqueda de información para plantear el problema, existen innumerables bases de datos y metadatos para recolectar información. Con el tema seleccionado, se 
ubican palabras clave y se puede intentar armar un algoritmo de búsqueda. El uso de filtros es necesario y útil, según el punto específico que se haya quedado en el ensayo. Se puede hacer una lectura rápida de abstract o del resumen para entender esa lectura y separarla para su análisis posterior.

Esta búsqueda permitirá elaborar un esquema inicial, si es posible crear fichas de información, crear hipótesis, objetivos y, finalmente la perspectiva teórica. En las fichas debemos extraer lo que realmente esté relacionado al tema a desarrollar; si no se hace, será tiempo gastado inútilmente. Puede separar las secciones a tratar, puede enumerarlas para luego utilizarla en la redacción final. Los objetivos expresan claramente el fin que se desea alcanzar en el ensayo; debe ser uno general y los específicos que apoyen a obtener el primero. Los objetivos específicos pueden también indicar separadamente, pero con unidad de sentido a todo el texto del ensayo. La hipótesis del ensayo es el supuesto o respuesta de lo que estamos investigando y debe estar basada en la información que fue seleccionada y consultada.

Puede empezar describiendo todo lo que se conoce sobre el tema, para luego establecer las brechas, lo que no se conoce y a dónde queremos llegar. Así se deja la pregunta que dirigirá el resto del ensayo y que, a su vez, está conectada al título.

Aquí se debe comunicar cuál es la perspectiva teórica que se está siguiendo para desarrollar el tema de estudio. Es necesario que cada párrafo vaya citado. A continuación, se muestra un ejemplo de introducción: 


\section{Figura 1}

Ejemplo de introducción de ensayo

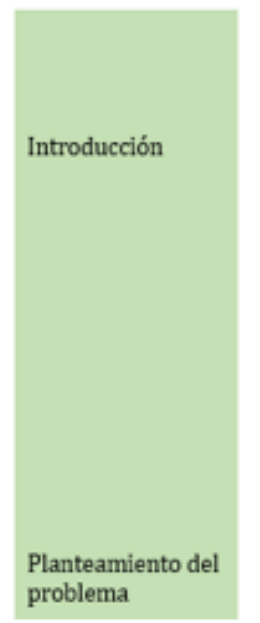

CAMBIOS EN LOS HÁBITOS ALIMENTARIOS EN LOS ESTUDIANTES UNIVERSITARIOS DURANTE LA PANDEMIA PRODUCIDA POR EL SARS-COV-2

Estudios revelan que los hábitos alimentarios (HA) de los estudiantes han sido alterados durante el periodo de confinamiento, viéndose un incremento en su ingesta de productos azucarados. ultraprocesados y, comidas rápidas (12). De igual manera, otros estudios han demostrado que hubo una disminuclón en cuanto a la ingesta de bebidas con contenido alcohólico (13). Por otra parte, se ha evaluado el impacto psicológico que ha sufrido esta población durante la crisis sanitaria, mostrando un desarrollo de diversas emociones como el miedo, angustia. molestia. irritabilidad. frustración. desmotivación. al igual que, un aumento en el estrés y ansiedad: asimismo, problemas de concentración $\mathrm{y}$ atención. dificultades para aprender y modificaciones en el sueño. No obstante, otras investigaciones realizadas señalan que los $\mathrm{HA}$ no se han visto afectados por los camblos que ha originado el SARS-CoV-2. o bien, que no se han mostrado camblos significativos (11). Entonces, es necesario reconocer si los HA de los alumnos universitarios se modificaron durante el periodo de cuarentena o si por el contrario. estos se han mantenido como eran antes de la pandemia. para tomar alguna medida en el aspecto nutricional con este grupo de edad.

\subsection{Desarrollo o cuerpo}

En el cuerpo se establece claramente la idea central del ensayo y debe tener como base los argumentos encontrados en las búsquedas de información científica. Se describen los aspectos vacíos que se tocaron en la introducción. Aquí, se escoge una técnica de argumentación para las ideas principales, o secundarias, que irán ayudando a sustentar el propósito del ensayo. Por ello, en el desarrollo, después de explicar el tema del ensayo y de argumentarlo, pasaremos a una discusión profunda del tema y a mostrar nuestra posición en relación a la idea central. Toda esta redacción no es por separado, sino que es continua, lo que implica una redacción coherente (Gómez-Martínez, 2020).

Si se está abordando un ensayo expositivo, es necesario describir la idea 
principal. Si se trata de un ensayo argumentativo se debe realzar la postura del autor, o descomponer y analizar el todo en sus partes, cuando el propósito es analizar un objeto. Cada párrafo empleado para sustentar la tesis debe concentrarse en una sola idea o argumento que la respalde.

Al mostrar nuestra posición en relación a la idea central, es importante recalcar que no solo quedará plasmado lo que se ha encontrado en las búsquedas, sino que también es necesario plasmar nuestro conocimiento: todo lo que se ha adquirido en la transferencia de conocimiento y consideramos necesario que otros lean, por su importancia para entender el fenómeno estudiado. A continuación, se presenta un ejemplo de desarrollo o argumentación:

\section{Figura 2}

Ejemplo de desarrollo de ensayo

\begin{tabular}{|l|l}
\hline Los hábitos alimentarios (HA) de los jóvenes universitarios suelen estar caracterizados por ser poco saludables, \\
debido a que son una población con tendencia a sufrir cambios constantes, especialmente por los que experimentan \\
en su formación académica. Se ha evidenciado que los alumnos universitarios ponen en práctica hábitos como el \\
omitir el desayuno, tener una ingesta baja de frutas y verduras, abusar del consumo de alimentos rápidos, consumir \\
caramelos o dulces durante el transcurso del día y tener una ingesta elevada de alcohol (16). Un estudio realizado a \\
estudiantes de una universidad en Colombia obtuvo como resultado que cerca del $70 \%$ de su población consumía \\
productos lácteos de manera diaria y la mitad consumían frutas. Asimismo, se observó una baja ingesta de verduras. \\
Cabe resaltar que el $10 \%$ de la población consumió alimentos chatarra de forma diaria y el $5 \%$, comidas rápidas (17). \\
Sin embargo, a lo largo del tiempo sus HA también pueden verse influenciados por diversos factores (1). Los cambios \\
en los estudiantes como la pandemia, han generado cuadros de estrés, temor y ansiedad. Otros estudios, han \\
mostrado que el estilo de vida de los estudiantes ha sufrido muchos giros con respecto tanto a su educación y su \\
economía, esto desencadenó un consumo emocional de forma diaria, lo cual se debe a que las emociones están muy \\
ligadas a la comida. Asimismo, en algunos estudios se ha destacado que la mayoría de la población confinada mostró \\
un interés en las prácticas de cocina en casa. En Uruguay, en una población conformada por más de 2000 estudiantes, \\
el $30,6 \%$ tuvo un aumento de peso. En lo que confiere a los HA, el $27 \%$ del total informó haber realizado cambios en su \\
alimentación. Se pudo evidenciar que el $56,1 \%$ había elevado su ingesta de alimentos fuentes de carbohidratos; \\
mientras que, por el contrario, había descendido su aporte de verduras y frutas. Asimismo, un $10 \%$ aumentó su \\
consumo de alimentos ultra procesados. También se encontró que el $33,5 \%$ disminuyó la actividad física (23).
\end{tabular}




\subsection{Conclusiones}

Aquí se describe el resumen del propósito del ensayo, y si fue aprobado o desaprobado según el proceso argumentativo; asimismo, se considera la opinión del autor. También suele colocarse los argumentos para generar la síntesis de todo lo mencionado a favor o en contra de nuestro propósito. Es propicio colocar alguna parte abordada en el ensayo y que puede ser un punto para iniciar una nueva investigación, o algo que se dejó fuera de contexto, pero puede ser relevante para continuar generando conocimiento (Jaramillo \& Mendoza, 2004; Creme \& Lea, 2000).

\section{Figura 3}

Ejemplo de conclusiones de ensayo

\begin{tabular}{l|l}
$\begin{array}{l}\text { Conclusión } \\
\text { (epílogo) }\end{array}$ & $\begin{array}{l}\text { Se encontraron estudios donde se evidenció que el consumo de alimentos saludables fue } \\
\text { mayor durante la pandemia que antes de esta. Se observó que las personas tenían mayor } \\
\text { poder en la selección de sus alimentos, sumándole la iniciativa de generar hábitos más } \\
\text { saludables como la práctica de actividades físicas, y del consumo de bebidas saludables y } \\
\text { alimentos correctos para la dieta. Otro grupo de estudiantes que han participado en los } \\
\text { estudios refieren un bajo ánimo durante la pandemia generando cambios en su estilo de } \\
\text { Síntesis de los } \\
\begin{array}{l}\text { argumentos. } \\
\text { Implicaciones }\end{array} \\
\begin{array}{l}\text { equilibrio emocional. Uno de los factores clave en los cambios alimentarios sufridos } \\
\text { durante la cuarentena, es el factor emocional, un bajo estado de ánimo, causado } \\
\text { principalmente por el confinamiento conduce a seleccionar alimentos menos saludables. }\end{array} \\
\text { Referencias bibliográficas } \\
\text { Referencias } \\
\text { Vera Ponce V, Raquel Torres J, Tello Quispe E, Orihuela Manrique E, De la Cruz Vargas J. Validación de escala de } \\
\text { cambios en los estilos de vida durante el periodo de cuarentena en una población de estudiantes universitarios de } \\
\text { Lima, Perú. Rev. Fac. Med. Hum. [Internet]. 2020 [citado } 15 \text { Oct 2020]; 20 (4):614-623. Disponible en: } \\
\text { http://revistas.urp.edu.pe/index.php/RFMH/article/view/3193/3412 }\end{array}$ \\
\hline
\end{tabular}




\subsection{Referencias bibliográficas}

Se debe incluir las referencias para lograr darle el marco científico al estudio, según sean utilizadas dentro del texto. El sistema de citado a usar dependerá del trabajo, de la especialidad y de las indicaciones del asesor o docente a cargo. Los sistemas más usuales son los acuerdos de American Psychological Association (APA) y el sistema Vancouver. Se sugiere revisar los respectivos manuales de la universidad.

\section{Referencias}

Anguiano M, Huerta J, Ibarra J; Almazán K. Manual básico para la escritura de ensayos. Estudios y propuestas de lenguaje y educación. Serie: Lenguaje, Educación e Innovación (LEI). Libros Digitales de Acceso Libre. Fundación SM de Ediciones México, A.C. Instituto de Evaluación y Asesoramiento IDEA. 2014 Disponible en: http://ideamex.com.mx/sites/default/ files/pdf/manual_basico_para_escritura.pdf

Cruz, M.E. (1997). Hacia una teoría general del ensayo: construcción del texto ensayístico.

Castro, M.C.;Hernandez, Laura y Sánchez, M.. (2010). El ensayo como género académico: una aproximación a las prácticas de escritura en la uni- 
versidad pública mexicana. Alfabetización Académica y Profesional en el Siglo XXI: Leer y Escribir Desde las Disciplin. 49-70.

Creme, P. (2000). Escribir en la universidad (Herramientas Universitarias) (Spanish Edition) (1st. ed.). GEDISA.

Gómez-Martínez, J. Teoría del ensayo. Vol. 36. Edic. Universidad de Salamanca, 1981. Locke, John. Ensayo sobre el entendimiento humano. Editorial Verbum, 2020.

Instituto Nacional de Salud. Breve guía de estilo para la redacción científca. Ministerio de Salud, 2007.

Jaramillo S, and Mendoza V. Guía para la elaboración de ensayos de investigación. Razón y palabra. 41 (2004).

Montaigne M, De Demócrito y Heráclito, en Ensayos, t. 1, Madrid, Cátedra, 2006, pp. 368-369.

Puentes, J. A la hora de escribir ensayos. Tabula Rasa 5 (2006): 209-227.

Rayas Rojas L, Méndez Puga A. Los estudiantes universitarios ante la escritura del ensayo académico: dificultades y posibilidades. Innovación educativa. (México, DF) 17.75 (2017): 123-147. 


\section{Elaboración de un Artículo}

\section{Científico}

Los artículos científicos son, por excelencia, el medio para comunicar, académicamente, de forma clara y precisa, documentada, los métodos, procesos y resultados de una investigación realizada. Su aplicación se da en todos los ámbitos de las ciencias. Se trata de una estructura lógica subyacente que busca que todo autor sustente los antecedentes de su investigación, demuestre la planificación de su estudio, su estructura conceptual, arroje resultados de prueba de hipótesis, incluso en los estudios descriptivos, elabore una discusión que dialogue sus temas como el estado del arte en general sobre dicho tema, y finalmente enliste las referencias siguiendo modos técnicos útiles para los avances en las ciencias de la información.

El objetivo de la presente guía es facilitar y orientar a los estudiantes en la realización de un artículo científico compatible con una publicación tipo artículo original y artículo original breve.

\subsection{Sobre el artículo científico}

El término artículo científico denomina de forma genérica los contenidos publicados en un journal o revista científica. De tal modo, esta denomi- 
nación incluye diversos géneros documentales o formas de publicación. Algunos de estos son: artículos originales, artículos originales breves, artículos de revisión, revisiones sistemáticas (con o sin meta-análisis), artículos de opinión científica, cartas al editor, cartas científicas, informes de casos (llamados reporte de casos o series de casos clínicos), comentarios académicos, editoriales, entre otros géneros que las revistas suelen definir según su línea editorial. De toda esta variedad de publicaciones potenciales, se suele precisar como paper al artículo científico que luego de un proceso de investigación comunica sus resultados a la comunidad científica. Definido así al artículo científico, al paper habrá que especificarle una estructura general más que un tipo de publicación en particular.

La forma más conocida de estructurar un artículo científico (o paper), adoptado por muchas revistas, se suele abreviar mediante el acrónimo IMRD, cuyas iniciales significan: Introducción, Métodos, Resultados y Discusión. Cabe resaltar que, además de lo mencionado con anterioridad, la propuesta de publicación debe contener el título, el resumen, las referencias bibliográficas y los anexos.

El objetivo de la Introducción es centrar y contextualizar el tema. Para ello, el investigador, que cumple el rol de autor, debe indicar en forma clara los fundamentos en los que se basa su estudio, el conocimiento que pretende generar y qué lo llevó a realizar el estudio. En palabras más directas, debe explicar las razones que justifican la realización del estudio y su objetivo 
específico.

En la sección de Métodos, se debe presentar la forma en que se ha realizado el estudio. Por ello su escritura deberá ser exhaustiva, con el fin de permitir que otro autor reproduzca el estudio total o parcialmente.

En los Resultados, se deben exponer solo las conclusiones a las que se llegaron en el estudio. Aquí debe considerarse que todos los comentarios del autor acerca de sus hallazgos deben ser reservados para ser ampliados en la Discusión.

En la Discusión, se enfatiza el significado y la importancia o relevancia que tiene el estudio. Cabe recalcar que en esta sección no se debe repetir la información que ya se ha colocado en las secciones anteriores. Por último, en este mismo apartado, se suelen describir las limitaciones y un último párrafo donde el autor escribe las conclusiones del trabajo.

\subsection{Generalidades antes de escribir}

Antes de iniciar una investigación, se requiere hacer una búsqueda de información o de literatura científica. Existen metadatos, y en ellos, una gran variedad de publicaciones confiables donde se puede encontrar artículos diversos. Esta recolección funciona como antecedente de nuestro estudio, es el punto inicial y la base de cualquier nueva publicación. Si el autor olvida este paso, puede cometer el grave error de iniciar un trabajo realizado 
con anterioridad por otros investigadores, lo que significa una gran pérdida de tiempo y recursos. Además de ello, buscar evidencia previa a la investigación supone una gran retroalimentación al estudio, ya que enriquece el panorama y permite diseñar de mejor manera la investigación. Por consiguiente, se debe hacer una autocrítica y reflexionar para tomar la decisión del propósito y la razón de ser de la futura publicación. Por ello, el autor debe plantearse, entre otras, las siguientes preguntas:

- ¿Se relaciona este trabajo con un tema actual?

- ¿Existe suficiente solidez sobre el tema y las hipótesis y objetivos tienen claridad en sus respuestas?

- ¿El estudio concluye con aspectos relevantes?

Si las respuestas de las preguntas son afirmativas, entonces puede proceder a plantearse la escritura del artículo. Esta primera fase es trascendental, ya que sienta las bases del enfoque que guiará toda la investigación. Incluso desde una perspectiva epistémica, se podría decir que esta fase no solo se restringe a la realización de una investigación, sino que constituye el día a día de la labor de un investigador: la construcción de su «punto de vista particular», el enfoque que le da a sus investigaciones, los paradigmas profundos que guían el modo en que el investigador encara a la realidad y la somete a sus preguntas singulares e inquietantes. 
El siguiente paso es elegir la revista a donde se piensa enviar el artículo. Esto es importante, ya que existe la posibilidad de que sea rechazado solo por haber escogido una revista incorrecta, ya sea en temática, fecha de recepción, etc. Una recomendación acerca de las posibles revistas candidatas para el envío de un artículo es guiarse por la editorial de los artículos a los que se ha consultado. Es pertinente conocer todas las directrices que posee cada revista para asegurar el interés de los editores y revisores por la temática del artículo. Para asegurar esto, es necesario haber seleccionado publicaciones actuales obtenidas en la revista elegida. Otro punto a considerar es si se trata de una revista incluida o indexada en bases de datos nacionales o internacionales. Esto permite ganar visibilidad cuando el artículo sea publicado, y también le otorga rigurosidad al proceso mismo de la publicación. Por otra parte, es necesario recordar que usualmente las revistas indizadas se encuentran saturadas de artículos para publicar, por lo que no le dan a cada artículo enviado la paciencia que eventualmente amerita. En suma, tener en consideración la revista a donde se piensa enviar el artículo científico constituye uno de los puntos de partida antes de emprender la escritura del mismo. También se debe verificar si la revista cuenta con un sistema de evaluación por pares, cuál es la velocidad en el proceso editorial y el factor de impacto obtenido por su tasa de citación. Muchos investigadores cometen el error de basar su elección únicamente en este último punto, que da como resultado la demora de la aceptación de su artículo. Es de suma importan- 
cia, una vez hayamos seleccionado la revista a la que enviaremos nuestro artículo, leer muy atentamente la Guía para autores, que se puede ubicar en la página web de la revista. De no hallarla, se puede optar por mandar un correo electrónico al editor de la revista, para realizar la consulta en cuestión. Este correo electrónico aparece en la sección de contactos, también localizado en la página web de la revista. En la guía para autores o instrucciones para el autor se especifica lo siguiente:

- La estructura del documento, desde la primera hoja, hasta el orden de las referencias

- El estilo bibliográfico

- El número de páginas y de palabras; si se requiere, número de líneas

- El orden de las tablas, características de las figuras, resolución de fotografías, entre otros

Es necesario que el artículo enviado cumpla con todos los requisitos mencionados en las guías para autor. De lo contrario, se perderá tiempo revisando secciones claramente establecidas en la guía para autores y/o que el artículo sea rechazado. 


\subsection{Preparación del artículo}

Al momento de iniciar la preparación del artículo original, primero se debe planificar su estructura. Para ello se divide en tres partes:

La primera parte nos permite establecer el tema a tratar, así como hacer atractivo e informativo el documento que escribimos. En esta parte, se debe incluir incluir el título, autores y sus filiaciones. Aquí también se debe especificar los datos del autor corresponsal, el resumen y las palabras clave.

La segunda parte contiene el cuerpo, y corresponde al artículo. Se subdivide en: Introducción, Métodos, Resultados y Discusión.

En la última parte se colocan los agradecimientos, referencias bibliográficas y los anexos. De igual forma, cabe mencionar que es posible que algunas revistas o journals exijan que los artículos enviados sigan una estructura diferente a la usual. Por ello, es importante revisar con anticipación las guías para autores, como ya se mencionó anteriormente.

Los artículos definidos como originales pueden plantearse y definirse a través de la respuesta de las siguientes preguntas:

- Introducción: ¿Por qué se ha hecho el estudio?

- Métodos: ¿Cómo se ha hecho el estudio?

- Resultados: ¿Qué se ha encontrado en el estudio?

- Discusión: ¿Cuál es la relevancia de mi estudio? 
Un aspecto que vale hacer notar es el siguiente: cuando se detalla la estructura modelo de un artículo original (extenso o breve) no se está haciendo mención a un tipo de investigación, sino a un modo de publicación, a un formato para publicar. Por eso la indicación de Introducción, Método, Resultado y Discusión debe tomarse solo en su condición de referente, ya que la propia revista es la que fija en última instancia la estructura de sus publicaciones. Existen, por otra parte, una serie de metodologías estandarizadas que a modo de criterios permiten ponderar la evidencia existente (por ejemplo: la metodología STROBE) y otras que tienen el mismo fin, pero con un cierto tipo de producción académica a partir de la revisión de la evidencia (como la metodología AGREE para guías clínicas, por ejemplo). Creemos de particular relevancia, para el caso de documentos observacionales, aplicar las exigencias de la metodología STROBE, que delimita en específico los puntos que debe tratar la introducción, la metodología, los resultados y la discusión. Si bien es propiedad de una revista fijar la estructura editorial de los documentos a publicar, en el caso que se está analizando —a través de artículos originales - puede ser de mucha utilidad para cualquiera que emprenda el camino de la escritura cotejar si sus contenidos coinciden con los que una metodología estandarizada pondera como calidad de la evidencia. 


\subsection{Estructura del trabajo}

\subsubsection{Primera página}

El título: Es importante redactar un título atractivo, ya que este busca provocar la curiosidad del lector y lo invita a revisar el texto. Al mismo tiempo, el título debe describir en pocas palabras el contenido del documento. Como se mencionó, el título debe contener un número suficiente de palabras (13 - 16 palabras), pero que explique el diseño que se ha seguido en el estudio. La información del título debe permitir recuperar electrónicamente el artículo de forma sensible y específica. Se debe tener en cuenta que el título del paper y el objetivo general de la investigación deben guardar concordancia.

Los autores y sus filiaciones: El International Committee of Medical Journal Editors nos menciona que los autores del artículo científico deben definirse sobre la base de su contribución individual y el grado de participación en la elaboración de dicho artículo. Así, es importante recomendar que los autores adopten una sola firma (forma de redactar los nombres de los autores) y no variarla en las posteriores publicaciones, en especial si se cuenta con apellidos o nombres compuestos. La identificación posterior en los sistemas automatizados de indexación puede dificultarse si no se tiene una firma invariable. Esto se refiere a la forma en que los autores redactamos nuestros artículos. Por ejemplo, si el nombre del autor fuera Eduardo Cáce- 
res Pérez, puede redactar su firma de autoría como "Cáceres, E", o también puede colocarlo como "Cáceres-Pérez, E”. Estas son dos formas de firmar su autoría. Se recomienda elegir una opción para todos los artículos en los que se trabaje, ya que facilita la búsqueda de la producción científica de un solo autor.

Autor corresponsal: Lleva el nombre completo del autor, el lugar donde labora, la dirección postal, de ser necesario, la dirección de correo electrónico, y el teléfono del autor. Esto es necesario para que la redacción de la revista se contacte con el autor corresponsal que es el nexo para mantener contacto con los otros autores.

Financiación y conflicto de intereses Encabezado o pie de página: Se redacta brevemente una descripción del artículo. Usualmente, no debe contener más de cuarenta (40) caracteres, lo que permite la filiación y la localización del mismo en las bases de datos (es opcional).

\subsubsection{Resumen}

Contiene los aspectos principales y los resultados relevantes esenciales con la finalidad de brindar en pocas palabras la información principal, el alcance, la metodología y los resultados del estudio. Su extensión puede ir de doscientas (200) a trescientas (300) palabras. Se debe tener en cuenta que esta es la primera y quizá la única parte que consultarán muchos lectores. Este apartado será el único utilizado en los sistemas de búsqueda 
bibliográfica, además del título y las palabras clave. Por ello, se deben transmitir brevemente y de forma concisa y concreta los puntos más resaltantes del trabajo. Se recomienda redactar el resumen después de elaborar el manuscrito, una vez que ya se tenga todos los puntos finalizados y una idea clara de la estructura orgánica de nuestro trabajo.

Usualmente, se opta por elaborar un resumen estructurado, similar a la estructura ya explicada para el artículo completo (introducción, objetivo, métodos, resultados y conclusiones). Sin embargo, es necesario recordar que las revistas son, finalmente, las que definen si el resumen debe ser o no estructurado.

\subsubsection{Palabras clave}

Este apartado, junto con el resumen, se encarga de otorgar visibilidad al manuscrito. Se deben elegir con mucho cuidado porque facilita que este sea hallado en los sistemas de búsqueda informatizados de las bases de datos. La mayoría de revistas exigen utilizar las palabras o términos que aparecen en el Medical Subject Headings (MeSH) de la National Library of Medicine.

\subsubsection{Introducción}

La introducción busca brindar contexto al trabajo. Aquí se expone el contexto y estado de la cuestión del tema investigado, ya sea si es un tema muy tocado por muchos investigadores o, por el contrario, un tema que muy 
pocos abordan. Es decir, se presenta la importancia del problema de la investigación del manuscrito. Puede dividirse en tres áreas o secciones que, para temas académicos, dividimos en preguntas:

- ¿Cuál es el problema de la investigación? (Planteamiento del problema)

- ¿Es el problema investigado importante y cuáles son la áreas o brechas por resolverse en la actualidad? (Justificación de la investigación)

- ¿Qué incógnita o vacío información busca responder con su trabajo?

En esta última parte, se debe detallar la hipótesis y el objetivo general del trabajo. Debido a la claridad y la forma concisa en que la introducción debe ser redactada, esta solo debe contener las referencias estrictamente necesarias para su elaboración. Tres o cuatro párrafos son más que suficientes para construir nuestra introducción. Si es muy larga, el lector no terminará de leer el artículo. Aquí no deben incluirse los resultados del estudio que se está publicando ni comparar o comentar los resultados a la luz de la evidencia previa.

\subsubsection{Métodos}

Aquí se expone la forma en que se realizó el estudio. Este apartado debe ser adecuadamente detallado, con el fin de permitir que otro investigador re- 
produzca total o parcialmente los resultados. Además, debe estar redactado en tiempo pasado y debe incluir la información disponible al momento de diseñar el estudio, ya que toda la información obtenida forma parte de los Resultados. Puede ir acompañado de las referencias bibliográficas consultadas en materia de la metodología del estudio. Este apartado incluye:

Diseño del estudio: Puede definirse a las investigaciones como estudios descriptivos o analíticos, observacionales o exponenciales, transversales o longitudinales, cuantitativos o cualitativos, entre otros criterios de importancia.

Población: Son los participantes del estudio. Estos pueden ser voluntarios, pacientes, animales, etc. También lo conforma el grupo control, si fuera el caso. Aquí se debe describir la localización donde se realizó el estudio, así como la forma en la que fueron seleccionados los participantes del estudio. Es muy importante que no se olvide mencionar los criterios de inclusión y exclusión que se tuvieron en cuenta para la selección de nuestra población. Se debe detallar además el proceso de asignación aleatoria que se siguió y el número de participantes de cada división que han finalizado el estudio. Por ello, también se debe incluir las razones por las que algunos participantes fueron retirados. Tanto como la definición de los sujetos de estudio, conviene precisar lo concerniente a la muestra y al muestreo. En ambos casos, es necesario detallar las precisiones estadísticas usadas (para el cálculo de la muestra) y las precisiones metodológicas de la técnica de muestreo, o, todo 
lo contrario, declarar explícitamente que ambas condiciones se realizaron por conveniencia o limitaciones de los investigadores.

Variables: Deben ser definidas claramente, y tener en cuenta que debe señalarse de forma clara y explícita la metodología por la que las variables fueron divididas, categorizadas y operacionalizadas. Se deben argumentar con evidencias las definiciones, los estándares, los criterios de validación (en caso de tratarse de variables definidas con instrumentos tipo test, por ejemplo), así como los proxys usados dentro del estudio. La definición de variables es un punto ineludible donde todo investigador debe evidenciar su dominio del tema y de los instrumentos a considerar.

Análisis de los datos: Se debe detallar las herramientas o softwares estadísticos utilizados, el valor de p que elegimos con el fin de señalar la significancia estadística de nuestro estudio, y las medidas del efecto analizadas en el estudio (OR, RR, número de pacientes que serán tratados, etc). Será necesario, para los estudios cuantitativos, detallar el tipo de análisis seguido según las condiciones de normalidad o no de las variables, ya que en muchos casos la aplicación de la técnica estadística incorrecta inhabilita cualquier tipo de resultado que se obtenga. Con el fin de agregarle validez a nuestro análisis, se recomienda señalar alguna cita bibliográfica, en especial si se utiliza un análisis poco habitual.

Aspectos éticos: Aquí se declara la aprobación del comité de ética, y el registro asignado del trabajo. Este debe ser aprobado por un comité de 
ética antes de comenzar a ejecutar la investigación para el levantamiento de datos. En caso que el estudio aborde humanos, se debe dejar constancia que se pidió los permisos correspondientes a cada uno de los participantes, como el consentimiento informado.

\subsubsection{Resultados}

Se debe colocar solo los hallazgos obtenidos en el estudio. Es necesario tener cuidado de realizar comentarios sobre los mismos en esta sección, ya que dichos comentarios deben ser puestos en la sección de Discusión. Nuestros resultados deben ser claros y explicados de manera completa y sencilla de modo que se facilite el entendimiento del lector. Para ello, se recomienda diseñar primero las tablas y los gráficos (gráfico de barras, histogramas, diagramas de cajas, entre otros), para que luego se redacte el texto pertinente a esta sección. Debido a que para esta sección también se cuenta con un límite, es necesario mantener a raya el número de tablas, figuras y/o gráficos (2 a 3 tablas o gráficos, aunque esto depende de las normas editoriales de la revista). Estas representaciones deben tener un título explicativo de forma individual y, a su vez, debe incluir el nombre de las variables que muestra, las unidades que se tuvieron en cuenta, las leyendas donde se explican puntos importantes de los gráficos y puntos de corte. En otras palabras, se debe brindar toda la información de forma precisa y completa para su interpretación, de modo que el lector entienda los gráficos por sí solos sin tener la 
necesidad de revisar el texto. Los datos deben ir de forma clara, ordenada y concisa sobre el hallazgo principal del estudio que gira alrededor del objetivo. Luego, se seguirá el orden ya mencionado en la metodología descrita con anterioridad. Los datos que se presentan en esta sección deben aparecer en porcentajes y valores absolutos. Se prefiere colocar ambos valores para evitar problemas y confusiones.

\subsubsection{Discusión}

Aquí se da énfasis al significado, los comentarios y la importancia del trabajo. No se debe repetir información escrita en las secciones anteriores (Introducción o Resultados). Es muy ventajoso comenzar esta sección describiendo fugazmente los hallazgos principales del estudio y, a partir de este punto, teorizar posibles explicaciones o razones a los hallazgos. Esto se realiza con el fin de contrastar los resultados con los resultados de estudios previos y que pueden tener más relevancia que el trabajo actual. Se debe considerar que es muy probable que algunos trabajos previos difieran de nuestros resultados. Por ello, se debe resaltar las razones y motivos que puedan haber llevado a esta variación de resultados, buscando explicar las diferencias. Es importante mostrar las limitaciones de nuestro estudio, demostrando compromiso con el método científico, además de darle menos razones al revisor o los redactores a criticar o rechazar el artículo. En esta misma línea, se debe enfatizar cuánta implicancia pueda tener el trabajo, así 
como relevancia en futuras investigaciones. Aquí también se debe mencionar los aspectos que quedan por rellenar y las líneas nuevas probables de investigación que se aperturen luego de nuestros hallazgos. Finalmente, en esta área debe incluirse las conclusiones a las que llegamos con nuestros hallazgos. Esto se basa en los resultados obtenidos en el estudio y debe incluir el mensaje que se desea transmitir a los lectores. Se debe tener cuidado de no establecer conclusiones que no se evaluaron en el trabajo; por ejemplo, no debe hacerse referencia a los costos de los resultados si el trabajo no ha incluido un análisis en ese sentido.

\subsubsection{Referencias}

Para muchas revistas, es de importancia y exigencia que sigamos las normas de la National Library of Medicine. Sin embargo, como ya se mencionó, es necesario que el autor consulte la guía para autores de cada revista probable a la que se desea enviar el artículo. Esto se hace con el fin de asegurarnos del formato y el estilo de la bibliografía. Se debe tener en cuenta que se incluyen las citas según su orden de aparición en el texto. Es necesario utilizar solo las referencias que aporten información relevante al artículo e intentar que no hayan alcanzado más de cinco años de antigüedad (salvo algunas excepciones que ameritan colocar referencias con mayor antigüedad). Tenga muy presente esto, ya que muchas revistas exigen un número máximo de referencias bibliográficas. De preferencia, se deben incluir citas que 
provengan de las fuentes originales y, solo en caso donde esto no se pueda asegurar, incluir citas comentadas por otros autores, mencionando en estos casos la fuente de consulta. Un punto a tener en cuenta es que los artículos que aún se encuentren en proceso de publicación pero que no estén publicados, deben considerar la palabra in press, siempre y cuando ya estén aprobados para publicación.

\subsection{Short Paper o artículo original breve}

Este tipo de artículos son aquellos que, por las características y el tamaño de sus objetivos, diseño y resultados, tienen la opción de ser publicados de manera abreviada, ya que su extensión puede no ser lo suficiente para entrar en la categoría de artículo original. En un artículo original breve, se describe una investigación que posee un menor contenido que el artículo original. Este tipo de manuscrito es muy apreciado por las revistas biomédicas, ya que en un menor espacio busca aportar resultados de una investigación de calidad.

Al igual que el artículo original, este tiene la siguiente estructura:

- Título

- Resumen no estructurado - 150 palabras

- Palabras clave 
- Introducción

- Métodos

- Resultados

- Discusión

- Referencias bibliográficas

Se considera como una extensión máxima de 2000 palabras, 4 figuras o tablas, y 20 referencias bibliográficas. La cantidad de referencias y otros parámetros son referenciales ya que siempre son las revistas las que se reservan el derecho de definir sus propios estándares. Tomando como referencia las instrucciones para autores de la Revista Peruana de Medicina Experimental y Salud Pública (RPMESP), es evidente que para cada tipo de artículo tiene diferentes límites en lo que respecta al número de palabras en el resumen, contenido del paper y número figuras, tablas y referencias bibliográficas. Para lo que concierne a la presente guía, el límite referencial que presenta la mencionada revista es: 
- Artículo Original: Resumen: 250 palabras

Contenido: 3500 palabras

\# Figuras y tablas: 6

\# Referencias bibliográficas: 30

- Short paper: $\quad$ Resumen: 150 palabras

Contenido: 2000 palabras

\# Figuras y tablas: 4

\# Referencias bibliográficas: 20

En lo que respecta a las palabras clave, la misma revista nos menciona que deben estar propuestas entre 3 y 10 palabras, tanto en español como en inglés. Para su selección, se incluyen los siguientes links:

- Descriptores en ciencias de la salud de la Biblioteca Virtual de Salud (BVS) (http://pesquisa.bvsalud.org/portal/decs-locator/?lang=es) para palabras clave en español

- MeSH NLM (http://nlm.nih.gov/mesh/)

\section{Referencias}

Ávila J. ¿Cómo redacto un artículo original? Orthotips. 2015; 11(2): 68 73. 
Mateu Arrom, L.; Huguet, J.; Errando, C.; Breda, A.y Palou, J. (2018). How to write an original article. Cómo escribir un artículo original. Actas urologicas españolas, 42(9), 545-550. https://doi.org/10.1016/j.acuro.2018.02.011

Casana-Jara, Kelly M. (2020). Características de la muerte de mujeres por violencia según las necropsias realizadas en la morgue del Callao. Revista Peruana de Medicina Experimental y Salud Pública, 37(2), 297-301. https://dx.doi.org/10.17843/rpmesp.2020.372.5111

Cardellach F, Ribera J. Tipos de articulo. Cuadernos de la Fundación Dr. Antonio Esteve. 2018; 9: 15 -23. URL: https://esteve.org/wp-content/uploads/2018 /01/13545.pdf

Centro de Investigación y Documentación de la Universidad Autónoma de Encarnación. Artículos Originales. URL: http://www.unae.edu.py/educacion/ima ges/recursos/6_articulos_originales CIDUNAE.pdf

Chambergo-Michilot D, Muñoz-Medina CE, Lizarzaburu-Castagnino D, LeónJiménez F, Odar-Sampé M, Pereyra-Elías R, et al. Migración para estudiar en escuelas de Medicina Humana del Perú. Revista Peruana de Medicina Experimental y Salud Pública. 2020;37(1):81-6. DOI: https://doi.org/10.17843/ rpmesp.2020.371.4695 
Guillén N, Llerena C, Samalvides S, et al. Riesgo de daño cerebral en prematuros menores de 34 Semanas expuestos a corioamnionitis histológica, Lima, Perú. Revista Peruana de Medicina Experimental y Salud Pública. 2020;37(2):229-38. DOI: https://doi.org/10.

17843/rpmesp.2020.372.4779

Instrucciones para autores. RPMESP. URL: https://rpmesp.ins.gob.pe/index.php/ rpmesp/pages/view/instrucciones

López-Guzmán C, Carmona-Fonseca J. Malaria Placentaria Submicroscópica: Histopatología y expresión de mediadores de procesos fisiológicos. $R e$ vista Peruana de Medicina Experimental y Salud Pública. 2020;37(2):2208. DOI: https://doi.org/10.

17843/rpmesp.2020.372.4759

Pallás J, Villa J. Artículo original (I): Introducción. Atención Primaria. 1998. URL: https://www.elsevier.es/es-revista-atencion-primaria-27-articulo-articulooriginal-i-introduccion-14896

Saavedra J. Factores Sociodemográficos y Eventos de Vida Tempranos Asociados con la Felicidad en Adultos de Lima Metropolitana. Revista Peruana de Medicina Experimental y Salud Pública. 2020; 37(1): 42 - 50. DOI: https://doi.org/10.17843

/rpmesp.2020.371.4580 
Valle R. Variabilidad de costos de antipsicóticos según establecimientos farmacéuticos en Lima, Perú. 2020;37(1):67-73. DOI: https://doi.org/10. 17843/rpmesp.2020.371.4899 


\section{Anexos}

- Ejemplos de artículos: A continuación, se presentan algunos ejemplos de artículos originales y de artículos originales breves (short papers). Esta muestra no busca ser total ni definitiva, sino solo pretende sentar las bases de recomendaciones generales sobre la escritura de un artículo original $\mathrm{u}$ original breve. Los docentes investigadores de la Universidad Privada Norbert Wiener son autores de esta breve selección:

- Artículos Originales

- Referencia: Lozada-Urbano, M; Miranda, D; Diaz-Contreras, J; Narro, R; Bartolini, R. Patrones de consumo y prácticas de alimentación de niños con y sin desnutrición, estudio en un área rural de Perú. Archivos de Medicina. 2019; 15(21):1-7. DOI: https://doi.org/10.3823/1413

- Referencia: Contreras-Pulache, H; Sevillano-Jiménez, J; Rodríguez-Saldarriaga, A; Moya-Salazar, J; Basurto-Ayala, A. Comprensión de lectura de artículos científicos en formato digital e impreso en estudiantes de medicina humana. Revista De Investigación (de la Universidad Norbert Wiener). 2021 10(1), 4-17. DOI: https://doi.org/10.37768/unw.rinv.10.01.001

- Referencia: Pardell-Dominguez, L; Palmieri, P; Dominguez-Can- 
cino, K; Camacho-Rodriguez, D; Edwards, J; Watson, J; LeyvaMoral, J. The meaning of postpartum sexual health for women living in Spain: a phenomenological inquiry. BMC Pregnancy and Childbirth. 2021;21:92. DOI: https://doi.org/10.1186/s12884021-03578-y.

- Referencia: Hernández-Vasquez, A; Chacón-Torrico, H; BendezuQuispe, G. Differences in the prevalence of cesarean section and associated factors in private and public healthcare systems in Per». Sexual \& Reproductive Healthcare. 2020; 26:100570. DOI: https://doi.org/10.1016/j.srhc.2020.100570.

- Referencia: Bonilla-Asalde, C; Rivera-Lozada, I; Rivera-Lozada. O. Determinants of Multi-drug Resistant Tuberculosis Treatment Failure in a prevalent region in Peru. PJMHS. 2020; 14(3): 1013-1018.

- Artículos originales breves (short papers)

- Referencia: Benites-Zapata, VA; Lozada-Urbano, M; UrrunagaPastor, D; Márquez-Bobadilla, E; Moncada-Mapelli, E; MezonesHolguín, E. Factores asociados a la no utilización de los servicios formales de prestación en salud en la población peruana: análisis de la Encuesta Nacional de Hogares (ENAHO) 2015. 
Revista Peruana de Medicina Experimental y Salud Pública. 2017;34(3):478-84. DOI:

https://doi.org/10.17843/rpmesp.2017.343.2864

- Referencia: Casana-Jara KM. Características de la muerte de mujeres por violencia según las necropsias realizadas en la morgue del Callao. Revista Peruana de Medicina Experimental y Salud Pública. 2020;37(2):297-301. DOI: https://doi.org/10.17843/ rpmesp.2020.372.5111 


\section{Sustentación de Casos}

Se presenta a continuación los criterios y condiciones para la conformación del estudio de casos como método de investigación en diferentes escenarios, como: a) caso clínico, b) caso educativo, c) caso administrativo y d) caso organizacional. Este capítulo se elabora con el propósito de servir como material de consulta y establecer una pauta para guiar al estudiante en la elaboración de casos, y promover que de su discusión se genere el intercambio de conocimientos y experiencias, lo que resultaría en un mejor aprendizaje.

El estudio de casos como método de investigación permite acercarse al contexto o situación de manera expedita, y es empleado para profundizar y ampliar el conocimiento del objeto de estudio. Metodológicamente, se aproxima al diseño o estructura de un estudio etnográfico (Stake, 1995). Además, es utilizado con frecuencia como método de investigación cualitativa. Se puede añadir que el estudio de casos incluye numerosas concepciones sobre la investigación, cuya característica básica es la averiguación en torno a un ejemplo o hecho concreto; esto con la finalidad de aproximarse a la comprensión de la realidad que actúa como un objeto de estudio.

De acuerdo con Yin (1993), en el contexto de la investigación naturalista o cualitativa, el diseño del estudio de casos adopta el abordaje de este 
paradigma. De allí que el estudio de casos puede emplearse para investigar en cualquier campo de conocimiento, asumiendo algunos de sus enfoques, tendencias o perspectivas.

\subsection{Sobre los casos}

Los casos se pueden asumir como recursos orientados a favorecer procesos de aprendizaje, profundos o significativos, que ayuden a desarrollar competencias profesionales e investigativas, en una visión de interrelación entre la teoría y la práctica.

Desde un estudio de casos, se puede realizar el abordaje de una teoría que podría ser empleada para comprender mejor el objeto de estudio, describirlo, evaluarlo o interpretarlo. Por esto, Stake (1994) los clasifica en:

1. Intrínsecos: Son utilizados para comprender mejor el caso que se haya diseñado, y profundizan en los elementos constitutivos que le dan sentido y significado.

2. Instrumentales: Se utilizan en la profundización de temas que contribuyen con el desarrollo del conocimiento y el surgimiento de teorías explicativas, descriptivas, interpretativas y hasta evaluativas.

3. Colectivos: En estos se eligen varios casos, dado que el estudio de todos puede favorecer la comprensión de algo más complejo y diverso, como una teoría que abarque diferentes aspectos del objeto de estudio. 
La idea principal de usar este tipo de métodos es formar profesionales capaces de dar solución a cada uno de los problemas que acontecen en sus profesiones, al presentar soluciones adaptadas al contexto social, humano y administrativo. Más allá de la descripción de situaciones, acontecimientos o realidades complejas, el estudio de casos contribuye con la sistematización de la recolección de evidencias. "Como en toda investigación, se recogen pruebas sistemáticamente, se estudia la relación entre variables y se planifica metódicamente la indagación” (Bell, 2005, p. 22). Es decir, el estudio de casos favorece el recorrido secuencial, coherente y organizado de las variables objeto de estudio.

De acuerdo con Muñoz (2011), el planteamiento, elaboración y asesoría de un estudio de caso requiere de los siguientes pasos: diseño del estudio de caso, elaboración del marco teórico o referencial, abordaje de la investigación, análisis de la información, interpretación de los resultados, y la incorporación de los elementos complementarios. Estos pasos se describen a continuación, a partir de la información que debe poseer el docente asesor y el estudiante investigador, de acuerdo al paradigma como sistema global de convicciones (Fernández, 2018).

1. Diseño del estudio de caso: Consiste en expresar en forma clara y precisa la estrategia a seguir para abordar el caso seleccionado, esto incluye la modalidad de investigación que se asumirá. De allí que el 
asesor debe ayudar al estudiante a seleccionar el enfoque y el diseño que más se adecúe al caso. A manera de ilustración, se presenta un ejemplo con la modalidad de investigación de campo, que de acuerdo con la UPEL (2016) se orienta hacia el "análisis sistemático de problemas de la realidad, con el propósito bien sea de describirlos, interpretarlos, entender su naturaleza y factores constituyentes" (p.18). Esto permite al tutor contribuir para que el estudiante logre ampliar y profundizar en el campo de conocimiento abordado y presentado como un caso de interés investigativo. Así, de acuerdo con los objetivos propuestos, el estudio de caso puede ser de campo, "de carácter exploratorio, descriptivo, interpretativo, reflexivo-crítico, explicativo o evaluativo"(UPEL, 2016, p.18). Esto implica asumir con responsabilidad la asesoría del estudio de caso, de acuerdo con la modalidad que mejor contribuya con el desarrollo de la investigación.

2. Elaboración del marco teórico o referencial: Es necesario que el asesor sepa diferenciar un marco teórico de un marco referencial, así como el uso que tienen según el paradigma de investigación asumido. El marco teórico contiene las teorías que sustentan el caso estudiado y deben ser asumidas por el investigador con el apoyo del asesor. Por otro lado, el marco referencial contiene la revisión amplia de la literatura relacionada con el caso, pero no se asume una teoría en par- 
ticular, sino que se va develando con el estudio del caso. A manera de ejemplo, se puede ver el marco teórico en los estudios desarrollados bajo el paradigma positivista, y el marco referencial en los estudios asumidos bajo el paradigma naturalista.

3. Abordaje de la investigación: Consiste en realizar una descripción de la metodología a seguir, tomando en cuenta el paradigma de investigación que se decida de acuerdo con la naturaleza del caso y la orientación del asesor. Allí, se considera el origen ontológico, es decir, el ser del caso estudiado, la dimensión epistemológica o la forma de generar conocimiento, la axiológica que responde a los valores predominantes y la dimensión teleológica que responde a los fines. Por ejemplo, en un estudio de caso desarrollado bajo el paradigma naturalista con enfoque fenomenológico, con la modalidad de campo, de carácter descriptivo, el asesor orienta hacia la clarificación de las dimensiones del caso. Esto apunta a que haya correspondencia entre el caso estudiado y el abordaje metodológico que se presenta a partir del método, técnicas, instrumentos, y procedimientos de análisis más adecuados al paradigma asumido.

4. Análisis de la información: Está referido al procedimiento a seguir para procesar los datos, que luego se convierten en información, y esta última en conocimiento. Así, el asesor puede orientar al estudiante de 
acuerdo al dato a ser procesado y analizado. Por ejemplo, si los datos son cuantitativos, se pueden procesar con el programa denominado SPSS. Si son cualitativos, se pueden procesar con el programa Atlas Ti. o Nudis. En tal sentido, el análisis de los datos cuantitativos es estadístico, a partir de las variables, y el de los datos cualitativos se da a partir de las categorías propias del estudio de caso desarrollado.

5. Interpretación de los resultados: La interpretación es un paso que requiere del asesor para que oriente en cuanto al procedimiento a seguir para aplicar la teoría asumida, ya sea si el caso responde al paradigma positivista o si la teoría que emergió responde al paradigma es naturalista. Bajo el paradigma positivista, se confronta la teoría con los resultados generados del procesamiento y el análisis. Es decir, se confronta los resultados con los objetivos planteados, se infiere y se concluye. Si el caso se desarrolló bajo el paradigma naturalista, el análisis se realiza desde la triangulación como técnica de análisis. La teoría se conforma a partir del comportamiento total del caso abordado.

6. Incorporación de los elementos complementarios: Acá, el asesor orienta en cuanto a los elementos a incorporar al estudio de caso de manera complementaria o como anexos; esto depende de la relevancia del elemento a incorporar. Puede, por ejemplo, sugerir que se incorpore 
el instrumento aplicado, el registro de campo, fotografías, entre otros.

En un estudio de casos, es importante conocer el desempeño del investigador al ser un observador de la realidad a la cual interroga o interpela, con la finalidad de caracterizarla en función de los aspectos comunes y diferentes encontrados en otras realidades.

De acuerdo con otros autores como Bell (2005), el estudio de casos tiene la finalidad de profundizar en la influencia que ejerce las características de una realidad estudiada sobre otra. Esta realidad puede estar conformada por actores, hechos o circunstancias, cuyas características presenten similitudes. Para cumplir con el objetivo, se hace uso de técnicas de recolección de datos o de información como la encuesta, con diferentes instrumentos como el cuestionario, lista de cotejo o escalas de estimación o de frecuencias, y la observación, utilizando la guía de observación, el formulario de registros o lista de chequeo, los cuáles permiten dinamizar el proceso investigativo (Rojas, 2007; Martínez, 2009).

A continuación, para efectos de la institución, proporcionaremos esquemas de estudios de casos: a) Clínicos, b) Educativos, c) Administrativos y d) Organizacional. Así, se tiene que los casos clínicos serían usados en las ciencias médicas; los casos educativos pueden ser utilizados por los estudiantes y profesionales de segunda especialidad, así como de Escuela de Posgrado; y los casos administrativos y organizacionales se utilizan en el 
campo administrativo, contable, jurídico y otras ramas públicas, como el derecho y las aduanas. 


\subsection{Carátula}

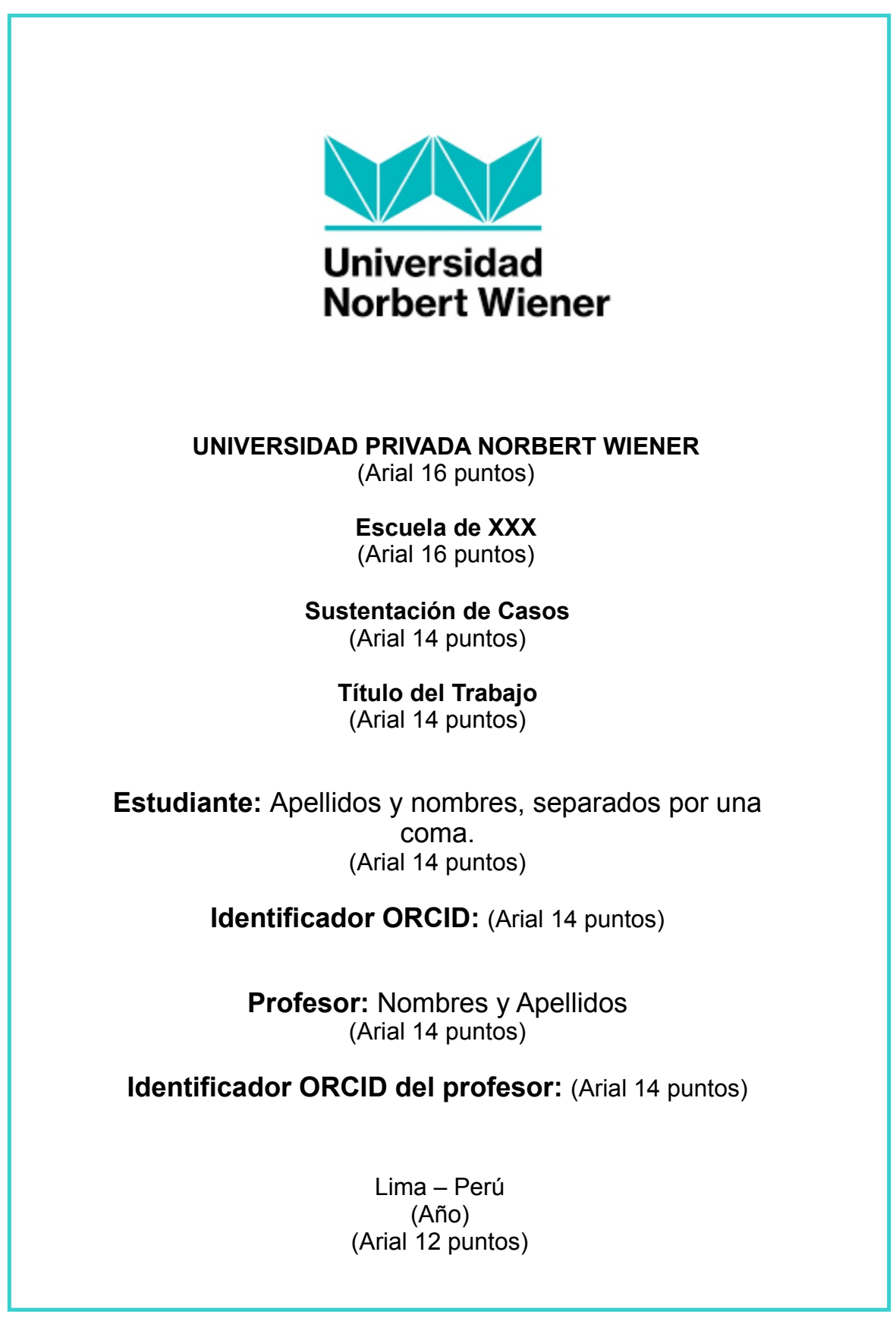




\subsection{Esquema para el estudio de caso clínico}

De acuerdo con el estilo de Vancouver, los casos clínicos se estructuran de acuerdo a la Lista de comprobación CARE (2013) para redactar un informe de caso de la siguiente manera:

1. Título: Debe ser expresado en forma clara y precisa, indicando la intencionalidad del caso objeto de estudio, con una extensión que no exceda las veinte (20) palabras. Debe ser un enunciado claro, preciso y que suministre la suficiente información relacionada con el contenido desarrollado en el caso clínico.

2. Palabras clave: Puede ser de 3 a 6 palabras. Se recomienda el empleo de términos MeSH (https://www.ncbi.nlm.nih.gov/mesh/) para adjuntarse al resumen en inglés y DeCS (https ://decs . bvsalud. org/E/homepa \gee.htm) para adjuntarse al resumen en español.

3. Resumen: Presenta de manera sucinta una visión general del caso desarrollado. Indica el propósito del caso, la revisión de los elementos teóricos fundamentales, el abordaje metodológico, modalidad de investigación, las técnicas e instrumentos empleados su validez o consistencia, así como la forma en que fueron analizados los resultados.

Además, debe contener una aproximación a la discusión de los resultados de acuerdo con el propósito y/o los objetivos formulados para 
indicar la conclusión o conclusiones a las cuales se llegó y la recomendación más relevante si fuera necesario. El tamaño o la extensión del resumen se calculan por el número de palabras, por lo que no debe exceder las trescientas (300) palabras. Es importante que el resumen incluya las palabras clave o descriptores.

4. Introducción: El objetivo es motivar al lector a que se interese con la investigación. Es conveniente revisar la literatura médica para investigar si el motivo por el cual se pretende difundir ya ha sido descrito a raíz de casos similares, cuántas veces y bajo qué circunstancias. En la introducción, es necesario realizar una amplia descripción del contenido del informe del caso clínico, y que destaque las fuentes teóricas que sustentaron el caso. Además, es necesario precisar brevemente el diagnóstico que sirvió de base para la profundización del estudio realizado, sin llegar a extenderse, pero sí indicando la estructuración dada al informe que se presenta.

La introducción debe invitar a la lectura crítica del caso. Debe destacar la importancia que tiene, y los aportes al campo de las ciencias al que corresponde. Debe también hacer referencia a la literatura consultada con énfasis en los autores más destacados de la temática tratada, así como los estudios previos o antecedentes vinculados con el caso. Es necesario tomar en consideración los avances realizados a nivel 
nacional e internacional, en función de la relación que tienen con el tema desarrollado.

5. Información del paciente: Se realiza con base a las interrogantes abordadas por el investigador al momento de dirigirse al paciente o al momento de realizar alguna entrevista a los expertos conocedores del caso tratado. Para ello, también puede presentar los resultados de los exámenes realizados a dicho paciente. En este sentido, es necesario resguardar la identidad del paciente en función de los compromisos éticos que deben estar presentes para preservar la valoración de la confidencialidad.

6. Hallazgos clínicos: Se debe brindar información sobre los hallazgos clínicos principales encontrados durante la evaluación inicial y evaluaciones de control del paciente. Se deberá reportar hallazgos clínicos positivos y/o negativos de relevancia para el caso en estudio.

7. Calendario: Se debe señalar hitos importantes relacionados al diagnóstico e intervenciones recibidas por el paciente. Si el caso en estudio presenta muchos eventos de relevancia a ser reportado, se recomienda presentarlos además en una tabla o una figura; por ejemplo, una línea de tiempo.

8. Evaluación diagnóstica: Es necesario incluir los antecedentes de im- 
portancia, diagnóstico y un posible tratamiento. Todo esto puede estar apoyado en los resultados de laboratorio, en los estudios radiológicos o en cualquier otro tipo de evidencia que sustente el caso planteado.

9. Intervención Terapéutica: Se debe informar sobre las intervenciones farmacológicas, quirúrgicas, preventivas, autocuidados u otros, recibidas por el paciente, dependiendo del caso estudiado. Asimismo, se debe brindar detalles sobre la administración de la(s) intervención(es); esto incluye dosis, concentración, duración u otro tipo de información de relevancia para el caso estudiado. Adicionalmente, se debe señalar si se presentaron cambios en la(s) intervención(es) recibidas por el paciente(s), y describir el motivo de este cambio (justificación).

10. Seguimiento y resultados: Información sobre los resultados, tanto desde la perspectiva del personal de salud como del paciente, deben ser informadas. Se debe reportar los resultados de mayor relevancia para el caso en estudio. Los resultados deben ser tanto los relacionados al diagnóstico de la enfermedad como los obtenidos durante el seguimiento del caso. Adicionalmente, se debe describir cómo fue dada la intervención(es) y tolerabilidad a la misma por parte del paciente. En caso se hubieran presentado, se debe describir los acontecimientos adversos e imprevistos durante la atención del paciente.

11. Discusión: Es una fase compleja que consiste en presentar los aspec- 
tos más significativos del caso tratado. Se toma en cuenta todos los elementos que lo conforman a partir del diagnóstico, las evidencias, los hallazgos y el tratamiento. La discusión del caso clínico representa una fase creativa, lógica y crítica para mostrar los resultados del análisis que se llevó a cabo a partir del significado que tiene para el avance del campo de conocimiento vinculado al sector salud.

Es fundamental desarrollar la discusión del caso clínico de manera sistemática, clara y organizada en función de la lógica de las ciencias de la salud y su correspondiente relación con los antecedentes encontrados en la literatura revisada. Al discutir un caso clínico se debe tomar en cuenta la información existente relacionada con el caso presentado, confrontar la teoría con la realidad del caso. De manera especial, se debe hacer distinciones entre situaciones o casos semejantes con el fin de establecer una perfecta claridad y comprensión del caso, para que no se confunda con alguno preexistente, que bien podría guardar relación, pero que se consideraría como un elemento de comparación.

12. Perspectiva del paciente: La perspectiva del paciente sobre su enfermedad es importante; es relevante que este pueda relatar su experiencia durante todo el proceso. Si en el desarrollo del caso el investigador tiene la posibilidad de obtener esta información, debe reportarla en la 
descripción del caso.

13. Consentimiento informado: En esta parte se debe describir si se obtuvo el consentimiento directo del paciente, de un cuidador o de un comité para este fin. El autor debe disponer de este documento en caso sea requerido.

14. Referencias: Estas constituyen el punto de partida para la verificación de la experticia teórica e investigativa que debe mostrarse en el caso clínico en función de la actualización evidente y necesaria, en cualquier caso. El sistema de citado a usar dependerá del trabajo, de la especialidad y de las indicaciones del asesor o docente a cargo. Los sistemas más usuales son los acuerdos de American Psychological Association (APA) y el sistema Vancouver. Se sugiere revisar los respectivos manuales de la universidad.

15. Anexos

- Ficha de identificación

- Galería fotográfica

- NOTA: Se muestra a constinuación algunos documentos que podrían ser útiles en el desarrollo del trabajo: 
[linatbución aval del proyecto tenctertble colocar nombre y logoll

\section{[Titulo del proyecto]}

Fecha: $\mathrm{XON} \times \mathrm{O} / 200 \mathrm{C}$. Versión $\mathrm{XX}$

Patroclnador: 00000000

In stitucion de investigacion: $x x x x c x x x x x x$.

Investlgador Principal: $000,500,000,000$.

Comite institucional de Etica para la Investigacion de la UPNW

Autorldad Reguladora Local: Insitula Nacionsi de Ssiud (INS)

\section{HOAA INFORMATINA}

\section{Introduccion}

Se le irmita a parioips en un estudio de irmesfigación dekido a que [oondoiones del

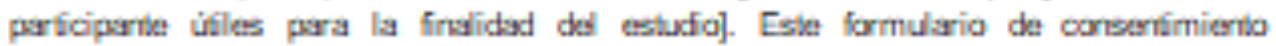
irformado induye irformacoán sabre el propósito del estuda, las riesgos para usied, y todo la que ocurrirá si usked desess parficips en el estuda. Por fovor, dese el fempo necoesario para revisar cuidadasamerite la irformacoín aqui trindada. En caso usted decida parfoips, se le solicitará que frme este documerta. De esta forma, su parficipsoión en este estudio será voluritaria.

Pida al irmesfigador del estudio a a las miembros del equipo ded estudia, que le explique cusiquer psistra o irformación de este consertimienta irformada, que no ertienda. Si decoide parfoips en este estuda, le serd́n reslizadas fo que se mexdrá a la irmerveróán que se le resdizará a las parficiparies] como parie ded estudia. Asimisma, usted serś irformado de cuslquer nuevo hallazgo que puexta suceder a la largo del estudio y que pueda afectar su corrinuidad en el estudia.

\section{Responsable del estudlo:}

B preserile estudia está sienda resdizado por [irvesigadar, insituoión]

Razon de reallzar el estudlo:

[maliva de reslizar el estudia].

\section{Metodologla del estudlo:}

[Describir de forma sernollla el estuda, describiendo las intervenciones, grupos de estudios y las varisbies que medirá].

\section{Particlpantes}

Podran particlpar:

[Tilulo del estudia]

Fedia: XONDOV200XC. Versión XXX 


\section{CERTIFICADO DE CON SENTIMIENTO INFORMADO}

He leida persorsimerte o me han leida el documerta completo de cornsertimierta irformado para la parfoipsoión en este estuda de irmestigsoión. Como polarnoisl participarta, he terido la coporturidad de hacer todes mis preguritas y corrsultas y estay corforme con las explicaciones recibidss. Por ella, acoedo volurtariamearte a parficipar en esile estudio fitulado ${ }^{\circ} \mathbf{X X}{ }^{\circ}$.

Dejo constancia de conocer que puedo refirsme en ouslquier mamerto durarta el

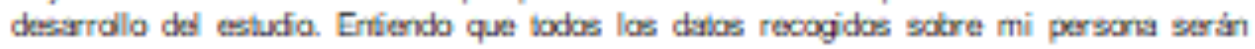
tratadas de conformidad con la legislación vigerie y se adaptarán bodes las precsuciones para gararifar la privacidad de los dabas, teriendo en ouerta las leyes de probecoión de datas ded Perú.

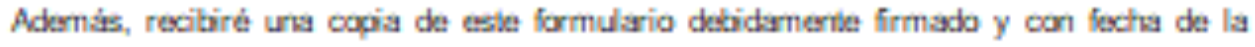
firms.

Firma del particlpante:

Nombre:

Fecha (Dis/Mes/Avio):

Hors:

Huella digital (En caso el participurte na sepsa lexer a escribir) 
[Listar crikerias de inclusión]

No podran particlpar:

pistar criverios de exclusión

La parfoipsoión en esta imvesfigación es completamerne voluritaria. Usted puede decidir si quere parfoipsr a na. De igus forma, usted puede cambiar de parecer más adelarite y dejar de parfojpr, incluso si estuvo de acuerdo artes.

Informacion sobre [lo que esta evaluando]

[licique de forma simple que se ssbe y que no de la que está evaluarida.

Procedimientos del estudlo

[incicar trevemerie que se reslizará y quienes reslizarán cada paso]

Duracion del estudilo

[serisla la duración general y segin cada fase del estudia]

Rlesgos al particlpar en el estudilo

[Describir, de haber, las riesgos que pueda preserilar el parioiparie]

Beneficlos de particlpar en este estudlo

[Describa quién recibe berneficio con las resulisdas del estudia, en algunas casas esta berneficio es para la sociedad, no habiendo un berneficio para el parficiparie]

\section{Compensacion}

[lndicar si el parfoiparie reoibirá algùn beneficio económioo o de olro fipo al parficipar en este estudio]

\section{Confldenclalldad de los datos recolectados en el estudlo}

[oomo se simacerará y probegerá las dalas de las parficipartes. Indicar quienes vendrán acoeso a las dalos y las formas en que las resuladas del estudio serán dfundidas, haciendo hincapié que en ringin mamerito se expondrán dajos que permitan idersficar al parficiparte del estudia]

\section{Contacto para mayor Informacion}

[indear que podrá corractarse con las irmesfigadares ded estuda (prinoipsl a miembros del equipa) durarie todo el curso del estudio (se deke indicar dajas de corriacta, induyenda email o colular. De igual forma, trinde las dajas de cornacta del cornité de éfica]

[Titulo del estudia]

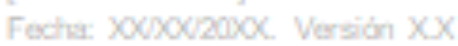




\section{CON SENTIMIENTO INFORMADO PARA FOTOGRAFIA CLINICA}

Yo,

del paciente o representante legal), con UNI $N^{*}$ :

(Nombre

por medio de la firma de este documento, autorizo la toma de una fotografia clinica por

parte de

determınado por esta persona para estatinalıdad. o un fotografo

Yo, autorizo el uso de las imägenes para las siguientes finalidades (marcar con un Check indicando Sio No)

_Si _. No...ser incluida en mi historia clínica

_Si _ No...ser usada con fin educativo a estudiantes de ciencias de la salud

- Si - No...ser publicada en articulos cientiticos de torma impresa o digital

_ Si _ _ No...ser presentada en congresos u otras actividades academicas

En cualquiera de las finalidades que autorizó el uso de estas imàgenes, mi identidad se mantendra estrictamente resguardada. La persona autorizada para el uso de las totogratas será responsable de resguardar mi identidad en el uso y distribución de las imágenes.

Declaro que se me ha explicado y he comprendido la finalidad de la toma de estas imagenes y se me ha permitido hacer preguntas sobre las mismas, siendo mis dudas aclaradas satisfactoriamente. Asimismo, señalo que se me ha informado que el no aceptar la toma de estas fotografias no repercute en la atenciön médica que recibo actualmente 0 en el tuturo.

A travès de este consentimiento, dejo constancia que no recibirè una remuneraciön econömica por las fotografias realizadas a mi persona.

Finalmente, dejo constancia que se me ha informado que, en caso decida retirar mi consentimiento informado, puedo indicarlo en cualquier momento, a través de un documento sımple redactado a la persona que le he brindado este consentimıerto informado.

(Firma del paciente o representante legal) (Fecha)

$\overline{\text { (Firma del profesional autorizado) }}$ (Fecha) 


\subsection{Esquema para el estudio de caso educativo}

De acuerdo con el estilo de las normas APA 7ma edición, los casos clínicos se estructuran de la manera siguiente:

1. Título: Debe ser expresado en forma clara y precisa, así como indican la intencionalidad del caso objeto de estudio, con una extensión que no exceda las veinte (20) palabras. Este debe ser, además, un enunciado claro, preciso y que suministre la suficiente información relacionada con el contenido desarrollado en el caso clínico.

2. Resumen: Presenta de manera sucinta una visión general del caso desarrollado. Indica el propósito del caso, la revisión de los elementos teóricos fundamentales, el abordaje metodológico, modalidad de investigación, las técnicas e instrumentos empleados su validez o consistencia, así como la forma en que fueron analizados los resultados.

Además, debe contener una aproximación a la discusión de los resultados de acuerdo con el propósito y/o los objetivos formulados para indicar las conclusiones a las cuales se llegó y la recomendación más relevante si fuera necesario. El tamaño o la extensión del resumen se calculan por el número de palabras, por lo que no debe exceder las trescientas (300) palabras. Es importante que el resumen incluya las palabras clave o descriptores. 
3. Palabras clave: Puede ser de 3 a 10 palabras.

4. Contextualización del problema y descripción: En todo estudio o trabajo de investigación, es necesario ubicar el contexto investigativo. Debe destacar las características del objeto o situación estudiada, para hacer énfasis en la situación problemática o problema.

De la contextualización del problema depende la ubicación temporal y espacial en la que ocurre lo que se investiga. Involucra aspectos culturales, sociales, políticos, económicos, educativos, tecnológicos, entre otros. Dependiendo del tipo de investigación que se realice, la contextualización del problema puede hacerse de manera inductiva (de lo particular a lo general), o de manera deductiva (de lo general a lo particular). Todo va relacionado con el paradigma de investigación que se asuma, sea naturalista o positivista.

En la descripción, se debe dar importancia a la unidad de análisis objeto del estudio, bien sea un estudiante, una institución o una convivencia cercana a la institución educativa. Así, se representa mejor la investigación, y se detallan sus particularidades, relaciones, vínculos, influencias o cualquier otra categoría o variable de interés para la investigación.

5. Protocolo de investigación: Representa el conjunto de normas a seguir durante el desarrollo de una investigación, desde la selección del tema 
a investigar hasta la elaboración del informe, su presentación y defensa. Debe tener énfasis en el abordaje metodológico, en el que cobra mayor importancia el diseño de la investigación, el cual depende del paradigma asumido.

De allí que el protocolo de investigación represente el esquema a partir del cual se desarrolla el estudio, sus pasos, fases o etapas relacionadas con el tipo de estudio y su forma de abordarlo. Además, incluye las consideraciones que deben ser tomadas en cuenta según sea el tratamiento que se deba dar a las variables para estudios positivistas o cuantitativos, o las categorías para estudios naturalistas o cualitativos. Cada investigación lleva implícita la descripción de los pasos, fases o etapas, que van desde el abordaje de la situación problemática, pasando por la revisión de la bibliografía, el tratamiento metodológico, el análisis e interpretación de resultados y la manera de presentar los hallazgos. Estos deben cumplirse con rigor y lógica científica.

6. Determinación el método de análisis: Consiste fundamentalmente en dar a conocer el camino a seguir para llevar a cabo el análisis e interpretación de los datos, sean cuantitativos o cualitativos. La determinación del método de análisis constituye la máxima expresión de comprensión del estudio que realiza el investigador, ya que el método responde a su lógica y a la lógica del campo de conocimiento. El 
propósito del método de análisis es el de contribuir con una verdadera aproximación a la validez y la confiabilidad en los estudios cuantitativos, así como a la confirmabilidad en los estudios cualitativos, en relación con la técnica y aplicada y el instrumento diseñado.

7. Organizar los datos obtenidos: Consiste en presentar los datos de manera que se observen claramente los elementos y relaciones entre ellos (al unificar lo cuantitativo con lo cualitativo) y la unidad de análisis. Los datos pueden ser organizados y representados en cuadros, gráficos, tablas o matrices, según sea el tipo de investigación que se desarrolle.

8. Conclusiones: En ellas se muestra de manera explícita el cierre del proceso investigativo al tomar en cuenta el propósito, las interrogantes y los objetivos en función de la discusión de los resultados. La fase conclusiva en un estudio de casos es de vital importancia para orientar hacia la continuidad de estudios similares, a la prosecución de aspectos que hayan quedado incompletos, o que hayan emergido o intervenido en el estudio sin haber sido considerados.

9. Establecer alternativas: De acuerdo a lo hallado en la investigación, las alternativas muestran posibles caminos a seguir o rutas de investigación que pueden dar origen al surgimiento de nuevas líneas de investigación o continuidad a las existentes. Esto debido a que permiten 
conocer hasta donde se ha podido avanzar en el campo de conocimiento de interés.

10. Referencias: El sistema de citado a usar dependerá del trabajo, de la especialidad y de las indicaciones del asesor o docente a cargo. Los sistemas más usuales son los acuerdos de American Psychological Association (APA) y el sistema Vancouver. Se sugiere revisar los respectivos manuales de la universidad.

\subsection{Esquema para el estudio de casos administrativos}

1. Título: Debe responder al estudio realizado, al mostrar las variables o categorías investigadas, así como el proceso administrativo abordado en el caso. Debe respetar las normas de elaboración del proceso investigativo, las mayúsculas y las negritas en el texto.

2. Resumen: El resumen es una exposición corta y clara del trabajo, donde se señala la ubicación, el objetivo general y/o propósito del trabajo, la principal actividad realizada, la metodología ejecutada, la conclusión y recomendación más significativa a juicio del autor.

Es necesario expresar el resumen en un texto no muy extenso que no exceda las trescientas (300) palabras. Debe destacar lo que se hizo, o lo que se investigó, cómo se llevó a cabo, dónde se realizó y con qué 
se realizó. Además, se debe colocar en la parte inferior en letra negrita las palabras clave o descriptores.

3. Antecedentes de la empresa: Se muestra la estructura de la actual organización, su visión (hacia dónde va la empresa), su misión (para qué fue creada) y los objetivos que se esperan alcanzar.

4. Funcionamiento: En esta sección, se puede mencionar cómo está constituida y organizada la empresa, al identificar las funciones, atribuciones y responsabilidades de las instancias administrativas.

5. Situación diagnóstica: Es la acción que permite obtener el análisis externo e interno de la empresa, y cuáles sus las debilidades, amenazas, fortalezas y oportunidades en el mercado laboral.

6. Abordaje teórico: Es la compilación sistemática de las fuentes de información bibliográfica pertinentes al trabajo, que constituye la plataforma conceptual del discurso utilizado por el o los autores.

7. Conclusiones: Las conclusiones deben dar respuestas en forma coherente y lógica a los objetivos planteados en el trabajo. Las recomendaciones son propuestas derivadas de las conclusiones, al mantener una armonía metodológica con los supuestos teóricos enunciados.

8. Referencias: El sistema de citado a usar dependerá del trabajo, de la especialidad y de las indicaciones del asesor o docente a cargo. Los 
sistemas más usuales son los acuerdos de American Psychological Association (APA) y el sistema Vancouver. Se sugiere revisar los respectivos manuales de la universidad.

9. Anexos: Esta sección tiene por finalidad proporcionar al lector material adicional que no pueda ser consignado en el cuerpo del texto, y sea considerado pertinente para su comprensión. Pueden ser incluidas tablas, figuras y otros contenidos que sirvan como referencia y ayuda a la comprensión del contenido a presentar.

\subsection{Esquema para el estudio de casos organizacionales}

1. Índice general: Se muestra la representación de la temática tratada en los diferentes capítulos, apartados, secciones o partes en las que se organiza el estudio, de tal manera que puedan ser identificados rápidamente, pues incluye el número de la página de su ubicación. Además, debe incluir la ubicación de los gráficos, figuras, cuadros, tablas o matrices utilizadas. También incluye el resumen, la introducción las páginas preliminares, las referencias y los anexos, al convertirse en una verdadera herramienta de localización rápida y segura de lo contenido en el estudio.

2. Resumen: Es una manera precisa de presentar el contenido del trabajo, su relevancia y propósito. Aquí, se señala, el objetivo general y/o 
propósito del trabajo, la principal actividad realizada, la metodología ejecutada, la conclusión y recomendación más significativa a juicio del autor. Debe ser escrito en lenguaje sencillo pero especializado, y ser de poca extensión, de trescientas (300) a trescientas cincuenta (350) palabras. Se coloca en la parte inferior y en letra negrita, las palabras clave o descriptores; estos deben ser los principales términos desarrollados en el contenido, de acuerdo con la UPEL (2016), cuando el resumen se elabora en otro idioma, “... siempre se colocan primero la versión en castellano" (p.38).

3. Introducción: Se realiza una presentación breve de la temática del trabajo, la relevancia, el propósito u objetivo del trabajo, la metodología utilizada, y la estructura general del Informe.

4. Objetivo general y objetivos específicos: El objetivo general debe comprender el qué, el cómo, el para qué y en dónde. Es decir, el título del trabajo y la acción a ejecutar sobre lo que se desea obtener, como fin último del trabajo. Se escribe utilizando verbos en infinitivo presente, tales como evaluar, analizar, proponer, explicar, comparar, verificar, entre otros.

Los objetivos específicos son las vías para lograr el objetivo general y se deben redactar en relación al mismo. Describen acciones de lo realizado y observado durante el período de pasantías y se utilizan 
verbos en infinitivo presente, tales como describir, realizar, observar, compilar, identificar, entre otros.

5. Capítulo I: Diagóstico de unidad de la organización. Contiene la descripción de la unidad de la organización y su área de influencia, tomando en consideración la identificación, denominación, ubicación, actividad principal, reseña histórica, visión, misión, valores, políticas, objetivos, metas, y organización.

6. Capítulo II: Bases teóricas. Es la compilación sistemática de las fuentes de información bibliográfica pertinentes al trabajo, que constituye la plataforma conceptual del discurso utilizado por el o los autores.

7. Capítulo III: Actividades realizadas. En este, se describen todas las actividades programadas por los tutores (académico y campo) y por el investigador, registradas a diario, con el material gráfico compilado. Además, incluye aquellas actividades complementarias que se generan durante el cumplimiento del período de actividad. Se detallarán las actividades realizadas de forma cronológica. De igual forma, se identifica el procedimiento empleado para llevar a cabo el trabajo.

8. Capítulo IV: Discusión. Aquí, se hace un análisis del proceso desde la perspectiva científica tecnológica. Se hace un análisis crítico entre los conocimientos teóricos y la práctica profesional, identificando as- 
pectos de relevancia en la formación del futuro profesional y como puntos críticos de control y de mejora.

9. Capítulo V: Conclusiones y recomendaciones. En las conclusiones, se expresa un análisis reflexivo, crítico, científico y técnico sobre la realidad percibida dentro de la unidad, así como la experiencia vivida dentro de la misma, a la luz del conocimiento adquirido en su formación profesional. Las conclusiones deben dar respuestas en forma coherente y lógica a los objetivos planteados en el trabajo. Las recomendaciones son propuestas derivadas de las conclusiones, y deben mantener una armonía metodológica con los supuestos teóricos enunciados.

10. Referencias y anexos: El sistema de citado a usar dependerá del trabajo, de la especialidad y de las indicaciones del asesor o docente a cargo. Los sistemas más usuales son los acuerdos de American Psychological Association (APA) y el sistema Vancouver. Se sugiere revisar los respectivos manuales de la universidad.

Los anexos del trabajo constituyen el conjunto de evidencias sensibles de lo realizado en cuanto a cronograma, instrumentos, presupuesto, y cualquier otro soporte de apoyo a la investigación, considerado de interés para una mejor comprensión e interpretación del caso tratado. 


\section{Referencias}

Bell, J. (2005). Cómo hacer tu primer trabajo de investigación. España: Gedisa. (Trabajo original publicado en 1999).

CARE. (2013), Lista de comprobación. https://www.actapediatrica.org.mx/wpcontent/uploads/2017/01/CARE-lista-de-cotejo-espa \%C3\%B1ol.pdf.

DeCS: https://decs.bvsalud.org/E/homepagee.htm

Fernández, B. (2018). Estudio de caso. Ponencia presentada en Primera Jornada de Investigación. Universidad Pedagógica Experimental Libertador UPEL: Instituto de Mejoramiento Profesional del Magisterio Sede. Apure. Venezuela.

Martínez, M. (2009). Nuevos paradigmas en investigación. Editorial Alfa. Colección Trópica Epistemología y Educación.

Merino-Trujillo A. Cómo escribir documentos científicos (parte 2). Caso clínico. Salud en Tabasco 2009; 15 (1):852-853. ISSN: 1405-2091. Disponible en: https://www.redalyc.org/articulo.oa?id=487/48712088007

MeSH: https://www.ncbi.nlm.nih.gov/mesh/

Muñoz, C. (2011). Cómo elaborar y asesorar una investigación de tesis. México: Pearson Educación. 
Pertuzé R. J. (2006). Criterios para publicar casos clínicos. Revista chilena de enfermedades respiratorias, 22(2), 105-107. https://dx.doi.org/10.4067/S0 717-73482006000200005

Rojas, B. (2007). Investigación cualitativa. Fundamentos y praxis. Fondo editorial de la Universidad Pedagógica Experimental Libertador (FEDEUPEL). Caracas.

Stake, R. E. (1995). Investigación con estudio de casos. Madrid: Morata, 1995.

UPEL (2016). Manual de Trabajos de Grado, de Especialización y Maestría y Tesis Doctorales. Universidad Pedagógica Experimental Libertados. $5^{\mathrm{a}}$ edición. Caracas.

Yin, Robert K. (1994). Case Study Research. Design and Methods. London: SAGE, 1994. 


\section{Elaboración de Monografía}

El presente capítulo fue elaborado con el fin de ser utilizado como material de consulta y establecer una pauta para guiar al estudiante en la elaboración de monografías, las cuales son un elemento importante para su desarrollo profesional. Por medio de su redacción, podrán ampliar sus habilidades y competencias investigativas, tan necesarias en el quehacer profesional de diferentes campos de acción.

Primero, se presenta una breve delimitación conceptual, junto con un esquema e instrucciones para el formato, con el fin de evitar confusiones con otros tipos de texto. Seguido a esto, se detalla por parte cada una de las secciones que componen la monografía, y se incluye ejemplos prácticos para el índice, citaciones y referencias.

\subsection{Sobre la monografía}

La monografía es un documento académico escrito que tiene como objetivo explicar o describir un tema previamente delimitado (Kaufman y Rodríguez, 1993; Ander-Egg y Valle, 2013). De acuerdo a Morales (2003), esta puede ser desarrollada por un autor o más y sirve también para llevar a cabo un análisis crítico de la literatura científica.

Por lo general, la extensión de la monografía es de 10 a 20 páginas. 
Sin embargo, es preferible priorizar la calidad del trabajo por encima de la extensión de este. Cabe tener en cuenta que, a diferencia de un ensayo, que es un texto breve de opinión subjetiva y de estructura libre, la monografía tiene un carácter más objetivo, organizado y tiene una función informativa (Rosas, 2006).

Para mantener el orden en la presentación de trabajos monográficos, se han estandarizado ciertos parámetros de forma. Se recomienda utilizar sangría de 0.5 al inicio de cada párrafo, un interlineado de 1.5 , márgenes de 2.5 en cada lado del documento, utilizar fuente Arial tamaño 11 o Times New Roman, tamaño 12.

\subsubsection{Esquema}

Carátula

Índice

1. Introducción

2. Cuerpo o contenido temático

3. Conclusiones

4. Referencias

5. Anexos 


\subsection{Carátula}

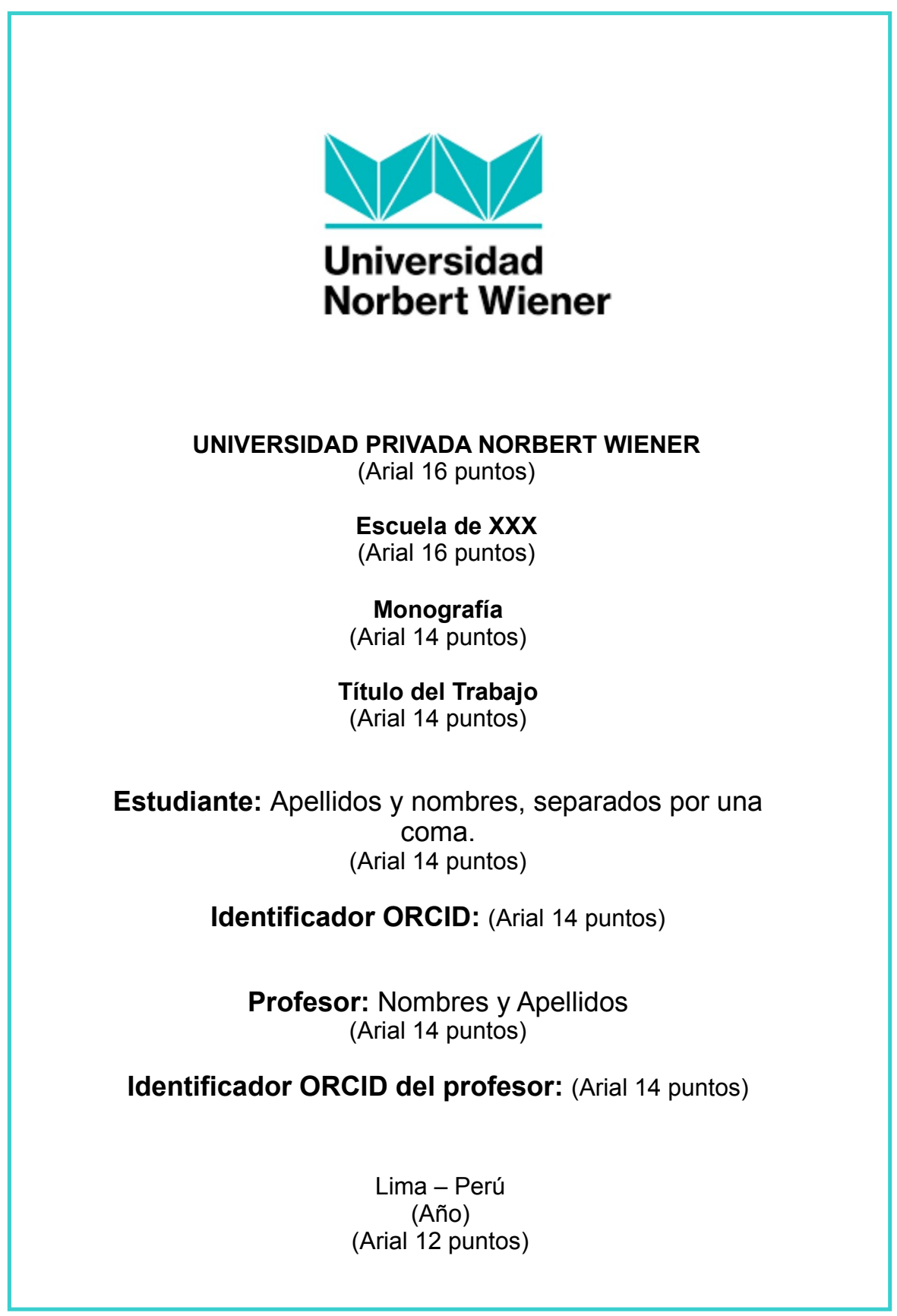




\section{3. Índice}

Este incluye una lista breve de los contenidos organizados de manera jerárquica e indicando la numeración para cada una de las secciones a tratar en el documento. Por ejemplo:

\section{Figura 4}

Ejemplo de índice de monografía

\section{INDICE}

Introducción
Cuerpo
Subtema 1
Subtema 2
Subtema 3
Conclusiones
Referencias
Apéndices

\subsection{Introducción}

Esta es la carta de presentación del trabajo. Esta sección debe dar un panorama general en donde se consigna el tema a desarrollar en la monografía, junto con las fundamentaciones prácticas y teóricas para realizar el trabajo. Es importante que en esta parte se detalle explícitamente la finalidad del trabajo monográfico, así se establece su importancia, con el fin de despertar el interés del lector y dar un breve adelanto de los contenidos a desarrollar 
(Morales, 2003; Gracida y Martínez, 2007).

\subsection{Cuerpo o Contenido temático}

En esta sección se desarrollan a profundidad las ideas planteadas en la introducción con ayuda de las referencias bibliográficas recopiladas (Morales, 2003). Aquí es posible hacer uso de subtítulos para direccionar y contrastar la información hallada, explicándola y redactando desde una óptica propia. En esta etapa, Carrasco Díaz (2009) recomienda la determinación y selección de ejes temáticos a detallar, pues refiere que es una de las tareas primordiales. Este proceso se deriva del tópico a tratar y de los enunciados, proposiciones y contenidos contextos relacionados. El procedimiento a usar para definir los ejes temáticos dependerá del tema principal seleccionado. Es importante resaltar que, siempre que se mencione una fuente de información o se haga alusión a alguna de sus ideas, se debe realizar la cita correspondiente, ya sea dentro del párrafo como al final de este (Gracida Juárez y Martínez Montes, 2007). Se sugiere revisar las guías de citado de la universidad.

\subsection{Pautas para la redacción}

Para realizar el trabajo monográfico, es recomendable seguir un procedimiento ordenado. Antes de empezar a redactar, es necesario delimitar la 
información temática. Esto servirá como criterio para seleccionar fuentes de información relevantes para la redacción del texto, lo cual a su vez determinará la calidad de la producción realizada. Se recomienda procurar que el tema elegido sea específico, ya que esto permite desarrollar a profundidad las ideas y mantener la coherencia en el desarrollo del texto (Sierra, 2013). Seguido a esto, es conveniente elaborar un esquema de trabajo preliminar que permita llevar un control de las actividades a realizar y mantener un orden en los contenidos conforme se van integrando.

Con estos pasos previos, es momento de hacer la búsqueda bibliográfica. Para esto, es conveniente iniciar con la revisión de fuentes de información primaria, es decir, aquellas que reportan información original o inédita, producto de un proceso investigativo, como artículos científicos, tesis, libros y otros medios confiables (Falcato, 2004).

Dependiendo del tema seleccionado, es importante consultar las fuentes de información secundarias, como las revisiones sistemáticas, guías, meta análisis y cartas al editor. Estas últimas representan muchas veces comentarios críticos de estudios originales, lo que suscita una discusión científica de carácter público. También las publicaciones terciarias forman parte de la exhaustiva búsqueda de la literatura científica en respuesta al desarrollo teórico especializado de una monografía, siendo en este caso: editoriales o artículos de opinión. Conocer este tipo de fuentes e identificar su ubicación brinda al estudiante una herramienta indispensable para poder recopilar, sistematizar 
y analizar información que le será útil en la construcción del marco teórico (Jiménez, 2011).

Es conveniente que la información sea actualizada. Esta puede ser hallada en forma de artículos científicos y que procedan de revistas indexadas. Con respecto a la antigüedad, esto va a depender del tipo de información que se seleccione.

Existen teorías que aún están vigentes y son muy antiguas, por lo que se debe colocar el año, solo si se tiene acceso al documento original. En el caso de los antecedentes o investigaciones realizadas sobre un tema en particular, es conveniente incluir los estudios recientes, de preferencia de los últimos 5 años. El uso de citas es restringido, y solo se utiliza en casos estrictamente necesarios.

Una vez recopilada la información se inicia con el proceso de redacción. Para ello, se pueden usar diferentes estrategias:

a) Elaboración de resúmenes: Los resúmenes representan síntesis de la información revisada, que incluye datos claves como la finalidad del trabajo, el método empleado, los resultados más destacados y las conclusiones a las que se llegaron (Sánchez Upegui, 2009).

b) Fichas bibliográficas: En ellas, se puede incluir las ideas extraídas de los textos que son de más utilidad para la redacción del trabajo académico (Mora Vargas, 2005). Esto funcionará como una referencia 
rápida y accesible que agilizará el proceso de producción intelectual.

c) Mapas mentales: Son herramientas muy útiles que pueden ayudar a esquematizar de manera visual los datos recopilados. Para este fin, se recomienda el uso del software XMind 2020 (https : //www . xmind . net/xmind2020/).

d) Lluvias de ideas: Cuando el trabajo es grupal, esta técnica suele ser muy útil para la generación de ideas, así como otras no menos importantes, como el Árbol de Problemas, Árbol de Objetivos, análisis FODA, entre otros.

\subsection{Sistematización de la información y ensamble teórico}

Esta fase constituye el análisis y discernimiento de la información recopilada. En ella se evalúa si es coherente con el tema propuesto, al comparar enfoques y teorías. Esto permitirá direccionar o redireccionar el trabajo monográfico. En esta etapa de producción intelectual es de mucha ayuda el uso de gestores bibliográficos, que facilitan y agilizan las tareas académicas. El avance de la tecnología ha permitido incorporar estos gestores en la modalidad de software, como Mendeley.com, EndNote note, RefWorks y Zotero, con muchos beneficios y utilidades. No solo permiten la automatización de las referencias, sino también la búsqueda especializada de información científica, ya que se encuentran sincronizadas con bases de da- 
tos de literatura científica como: BVS, PubMed, Wiley Open Access, Redalyc, Scielo, Springer Open, Dialnet, ERIC, Clacso, Scopus, Sciendirect, ProQuest, Ebsco, entre otros (Varón Castañeda, 2017). También se les denomina la biblioteca del investigador, porque no solo tiene uso instrumental. Promueven además habilidades investigativas y permiten establecer redes sociales-colaborativas con otros investigadores.

\subsection{Conclusiones}

En este apartado, se incluyen las deducciones realizadas a partir de la revisión exhaustiva de la literatura científica y elaboración de los contenidos del trabajo. Asimismo, se reportan los hallazgos, que dan respuesta a las preguntas planteadas en la introducción y acorde a los objetivos planteados. Además, se pueden añadir pautas para futuros estudios basadas en la experiencia vivida al realizar cualquiera de las fases del trabajo monográfico (Gracida Juarez y Martínez Montes, 2007). Toda esta información se redacta en párrafos breves.

\subsection{Referencias}

Se debe incluir las referencias para lograr darle el marco científico al estudio, según sean utilizadas dentro del texto. El sistema de citado a usar dependerá del trabajo, de la especialidad y de las indicaciones del asesor 
o docente a cargo. Los sistemas más usuales son los acuerdos de American Psychological Association (APA) y el sistema Vancouver. Se sugiere revisar los respectivos manuales de la universidad.

\subsection{Apéndices}

Esta sección tiene por finalidad proporcionar al lector material adicional que no pueda ser consignado en el cuerpo del texto, y sea considerado pertinente para su comprensión. Pueden ser incluidas tablas, figuras y otros contenidos que sirvan como referencia y ayuda a la comprensión del contenido a presentar (American Psychological Association, 2020). 


\section{Referencias}

Acuña Gamboa, L. A. (2018) Formación de investigadores educativos en Chiapas: Realidades y falacias. Revista Latino Americana de Estudios Educativos, 48(1), 103-142. https://www.redalyc.org/jatsRepo/270/27057919009 /html/index.html.

American Psychological Association. (2020). Publication manual of the American Psychological Association (7th ed.). American Psychological Association. https://doi.org/10.1037/0000165-000

Ander-Egg, E., \& Valle, P. (2013). Cómo elaborar monografías, artículos científicos y otros textos expositivos. Universidad Inca Garcilaso de la Vega.

Carrasco Díaz, S. (2009). Metodología de Investigación Científica: Pautas metodológicas para diseñar y elaborar el proyecto de investigación. Lima: Ed. San Marcos. http://www.biblioteca.une.edu.pe/cgi-bin/koha/opacdetail.pl?biblionumber $=65302$

Falcato, P. (2004). Guía de fuentes de información especializadas: humanidades y ciencias sociales / Susana Romanos de Tiratel. 2a. ed. Buenos Aires: GREBYD, 2000. 281 p. ISBN 987-98052-1-6. Información, Cultura Y Sociedad, (5), 98-100. https://doi.org/10.34096/ics.i5.1000 
Gracida Juárez., M. I. y Martínez Montes, G. T. (2007). El Quehacer de la Escritura. Propuesta Didáctica Para la Enseñanza. Universidad Nacional Autónoma de México.https://portalacademico.cch.unam.mx/materiales/lib ros/pdfs/librocch_ quehacerescritura.pdf

Jiménez, J. M. (2011). Tipos de Publicaciones Científicas. COLUMNA, 1(4), 91-96. https://www.medigraphic.com/pdfs/columna/col-2011/col114 e.pdf

Kaufman, A., y Rodríguez, M. E. (1993). La escuela y los textos. Santillana. https://teachingpnieb.files.wordpress.com/2017/05/d2-d3-kauffman-2003-laescuela-y-los-textos.pdf

Mora Vargas, A. I. (2005) Guía para elaborar una propuesta de investigación. Educación, vol. 29, núm. 2, pp. 67-97. Universidad de Costa Rica San Pedro, Montes de Oca, Costa Rica.

Morales, O. A. (2003). Fundamentos de la investigación documental y la monografía. Manual para la elaboración y presentación de la monografía. Universidad de Los Andes.

Rosas, Z., E.L. (2006). El texto académico: una aproximación a su definición. Revista voces, tecnología y pensamiento, 1, 127-135. 
Sánchez Upegui, A. A (2009). Los resúmenes para artículos de investigación. Revista Virtual Universidad Católica del Norte, 26. pp. 1-9. Fundación Universitaria Católica del Norte Medellín, Colombia.

Sierra, G. M. (2012). Cultura investigativa. Opciones de Grado - Programas de Pregrado. Universidad EAN. Recuperado de: http://hdl.handle.net/10882 13210 .

Varón Castañeda, C. M. (2017). Gestores bibliográficos: recomendaciones para su aprovechamiento en la academia. Journals \& Authors. http://biblioteca digital.udea.edu.co/bitstream/10495/7607/1/VaronCasta

nea_2017_GestoresBibliograficos.pdf 


\section{Elaboración de Tesina}

La tesina constituye una forma coherente de presentar los resultados de la investigación realizada con profundidad temática, de acuerdo con las normas, criterios y procedimientos que establezca la institución. Es una investigación en la que el estudiante investigador demuestra sus capacidades o competencias investigativas. Este documento constituye el producto final del proceso formativo e investigativo, orientado a la consecución de un grado académico empleado en el pregrado o formación inicial como requisito para obtenerlo. Así, el estudiante investigador podrá generar, desde su propia experiencia, diferentes formas de abordar la realidad teórica objeto de estudio.

Con la tesina como producto investigativo, el estudiante investigador demostrará las competencias desarrolladas durante su formación profesional, entendidas como un sistema complejo de interacción cognitiva, socioafectiva, conductual o práctica y ética. A partir de este sistema, se lleva a concreción la búsqueda de alternativas conceptuales soportadas en documentos o fuentes bibliográficas, con carácter y rigor científico. 


\subsection{Sobre la tesina}

La tesina es un informe científico que representa una forma acertada de presentar los hallazgos de una investigación cuya metodología responde a los requerimientos del paradigma, enfoque, modelo o perspectiva asumida por la institución para este tipo de informes. Su profundidad se orienta por la ampliación o profundización del saber en un campo de conocimiento determinado, asociado a las carreras que se ofertan.

Las tesinas son "trabajos integradores del conocimiento que se producen como corolario de una carrera de grado. Los escollos que encuentran los estudiantes para realizarlos proceden de diferentes condicionamientos como los discursivos, socioindividuales, institucionales" (Bitonte, 2019, p. 139). Las tesinas son la forma de buscar una solución a un determinado problema a través de un proceso sistemático, "ello incluye la producción de información válida y confiable y requiere la realización de ciertas etapas para asegurar que la solución al problema también sea válida" (Quintana y Hermida, 2020, p.12).

La complejidad de una tesina depende del alcance de la investigación asumida y, en consecuencia, del abordaje que le imprima el estudiante investigador, al determinar los elementos que deben ser considerados para dar sentido y significado al tema tratado. Así, se requiere de técnicas de recolección y de análisis e interpretación de los datos obtenidos en el muestreo 
teóricos.

La tesina debe mostrar los resultados de una investigación eminentemente documental sobre un tema del campo de conocimiento de la formación profesional. Esta investigación es realizada por el estudiante investigador, con la debida profundización y sustentación en la revisión de la literatura relacionada con la temática de interés.

De acuerdo con la UPEL (2016), la investigación documental constituye "el estudio de problemas con el propósito de ampliar y profundizar el conocimiento de su naturaleza, con apoyo principalmente en trabajos previos, información y datos divulgados por medios impresos, audiovisuales o electrónicos" (p.20). Esto significa que en una tesina el apoyo teórico proveniente de este tipo de fuentes es realmente importante.

\subsubsection{Características}

La tesina es un informe científico, caracterizado por ser: a) creativo, b) innovador, c) preciso y d) original. Es de carácter documental y monográfico, referido a la base teórica y conceptual que dinamiza el conocimiento en áreas específicas sin descuidar el procedimiento, la estrategia y la técnica a emplear. De acuerdo a Cubo (2007), la tesina tiene la función de informar acerca del proceso investigativo y los resultados obtenidos, al presentar diferentes puntos de vista que pudieran orientar acerca de posturas, visiones o perspectivas relacionadas con la naturaleza del conocimiento objeto de la 
investigación realizada.

El tema debe ser relevante y relacionado con la disciplina o campo de conocimiento del estudiante investigador. Además, debe estar orientado por un tutor, asesor o mentor con formación en el campo profesional respectivo y en investigación de tipo documental, por ser la de predominio de una tesina. Esta debe también ser sustentada o presentada ante un jurado evaluador o comité de especialistas en la materia para ser sometida a su aprobación, de acuerdo con criterios de evaluación fijados previamente por la instancia respectiva.

De acuerdo con Argota-Perez et al. (2020), el propósito de la tesina es enriquecer la disciplina o de innovar con algún planteamiento sustentado. La demostración de competencias profesionales resulta un proceso de desarrollo educativo, el cual puede medirse mediante la introducción social de resultados prácticos investigativos que sean diferentes a ciertos enfoques tradicionales, de acuerdo con el tipo de investigación documental empleado. Según la UPEL (2016), la investigación puede ser de los siguientes tipos:

a) Investigaciones de desarrollo teórico, referidas a elementos conceptuales e interpretativos generadas del análisis y la interpretación de los datos referidos a un tema en particular.

b) Investigaciones referidas a la revisión crítica del comportamiento teórico del campo de conocimiento, que permiten organizar, integrar y 
evaluar o valorar la información existente en relación al campo de conocimiento abordado.

c) Estudios comparados, que permiten mostrar las características, semejanzas y diferencias teóricas existentes de acuerdo con los enfoques y tendencias del campo de conocimiento.

\subsubsection{Estructura}

Con la instrumentación de la tesina, se incursionará en el mundo de los proyectos científicos, del pregrado o de la formación inicial, como parte de la experiencia que se pretende impulsar en la institución. Para ello, se presenta la estructura que debe poseer este informe de investigación, que debe seguir el rigor metodológico de una investigación de tipo documental y organizarse en capítulos.

Carátula

Índice

1. Introducción

2. Situación Problemática

3. Justificación e importancia de la investigación

4. Formulación de los objetivos o propósitos de la investigación 
5. Marco teórico o referencial

6. Aspectos metodológicos

7. Resultados

8. Conclusiones

9. Referencias 


\subsection{Carátula}

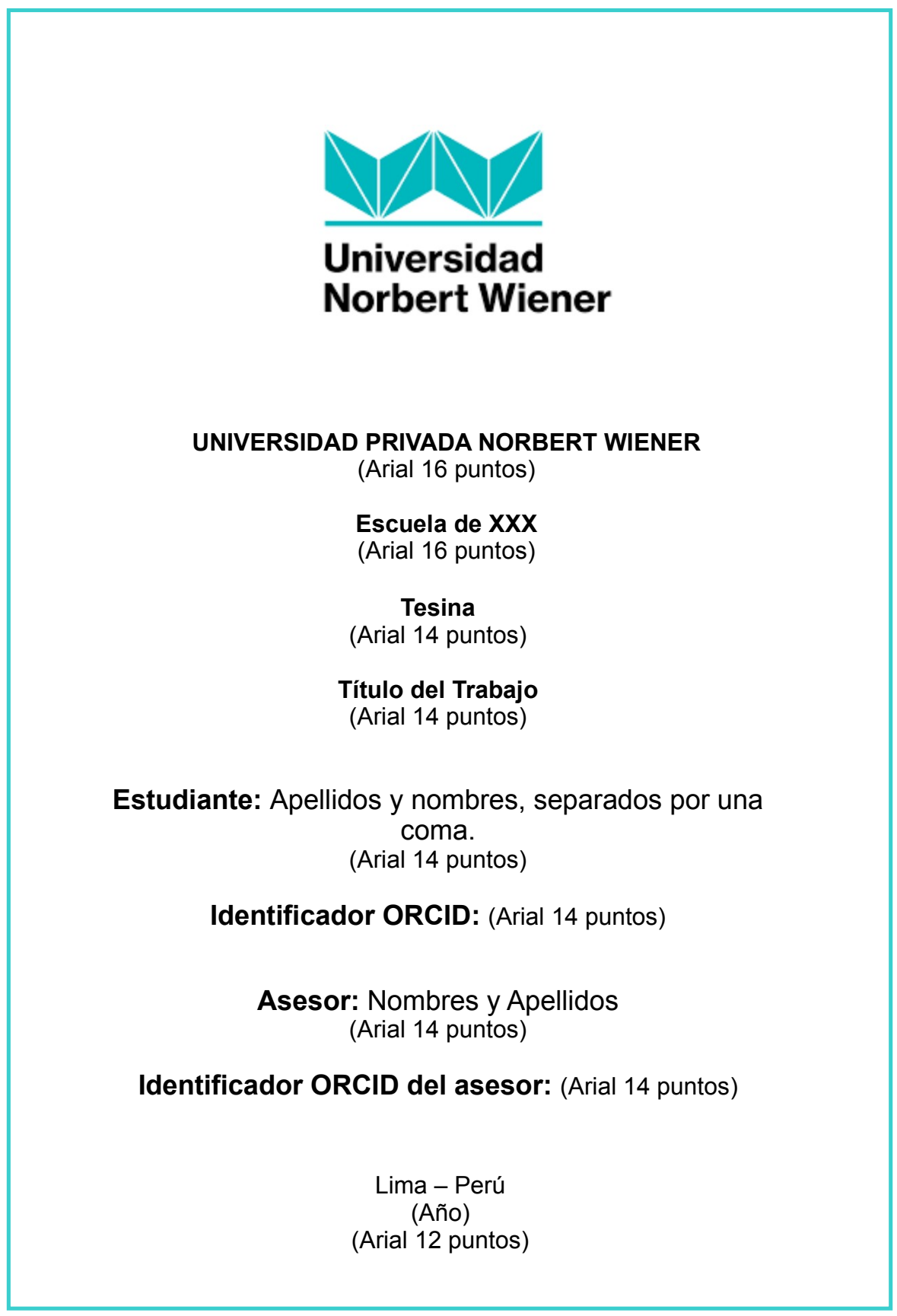




\section{3. Índice}

Contiene la lista de los apartados contenidos en la tesina. Este indica el número de página en el que comienza cada uno de ellos. Se debe incluir la relación de contenidos que se desarrolla en la tesina, ordenados por capítulos y subcapítulos, anexos, entre otros.

\subsection{Introducción}

Consiste en una descripción clara y concisa del abordaje realizado, sea por tema, o por problema investigado. Debe proporcionar la información necesaria acerca del contenido general de la tesina. Es necesario explicar las razones que lo llevaron a realizar la investigación y por qué fue elegido ese tema de investigación, además de indicar el propósito y alcance de la investigación.

\subsection{Situación problemática}

La situación problemática muestra la descripción del contexto a ser investigado, ya que muestra detalladamente lo más relevante del trabajo realizado, su viabilidad y pertinencia, dentro de sus tiempos y recursos disponibles. El abordaje de la situación problemática muestra claramente el problema tratado, su origen y las interrogantes orientadoras tales como: 
1. ¿Qué tema se quiere tomar como eje de la investigación?

2. ¿Por qué y para qué?

3. ¿De dónde se parte y adónde se pretende llegar?

\subsection{Justificación e importancia de la investigación}

Se expresan las razones que motivaron el desarrollo de la investigación, así como el aporte teórico que se genera al campo de conocimiento abordado y su relevancia, al definir lo que se busca de esta investigación.

\subsection{Formulación de los objetivos o propósitos de la investigación}

Los objetivos o propósitos (según sea el paradigma de investigación asumido) expresan lo que se pretende lograr al término de la investigación, es decir, fijarán el alcance del problema. Estos deberán ser concretos, evaluables, viables, alcanzables, y relevantes. Un objetivo o propósito debe redactarse con verbos en infinitivo que se puedan evaluar, verificar y refutar en algún momento dado.

\subsection{Marco teórico o referencial}

Se describen brevemente las teorías, enfoques teóricos, postulados, conceptos, y otros aspectos conceptuales que sustenten el abordaje y/o cons- 
trucción del objeto de estudio y toda la investigación en general. Este punto es muy importante, puesto que proporciona la seriedad académica pertinente.

\subsection{Aspectos metodológicos}

El abordaje metodológico que corresponde a la tesina es el de una investigación documental. En él, se describen las estrategias, técnicas y/o procedimientos a seguir, los instrumentos a ser utilizados para obtener los datos, y su análisis e interpretación.

\subsection{Resultados}

Los resultados deben mostrar el análisis e interpretación, además de incluir las evidencias en función de su discusión de acuerdo con los objetivos o propósitos planteados.

\subsection{Conclusiones}

Se pretende que el estudiante redacte, con sus propias palabras, las experiencias vividas. Van acorde al número de objetivos planteados en la investigación. 


\subsection{Referencias bibliográficas}

Se debe incluir las referencias para lograr darle el marco científico al estudio, según sean utilizadas dentro del texto. El sistema de citado a usar dependerá del trabajo, de la especialidad y de las indicaciones del asesor o docente a cargo. Los sistemas más usuales son los acuerdos de American Psychological Association (APA) y el sistema Vancouver. Se sugiere revisar los respectivos manuales de la universidad.

\section{Referencias}

American Psychological Association. (2020). Publication manual of the American Psychological Association (7th ed.). American Psychological Association. https://doi.org/10.1037/0000165-000

Argota-Perez, G.; Doroteo-Neyra P., Chacaltana-Ramos L., Peñaranda-Calle, C., Roca-Vásquez K., Gutierres-Ramos E., \& Velásquez Salcedo L. (2020). Investigative Training For The Prospective Learning And Metodologic In University Students. PAIDEIA XXI. Vol. 10, № 2, pp. 407-415http://revistas.u rp.edu.pe/index.php/Paideia/article/view/3442/4238

Bitonte, M. E. (2019). Tesinas y géneros de graduación: Traslaciones. Revista Latinoamericana de Lectura y Escritura, 6(11), 139-159. Recuperado 
a partir de http://revistas.uncuyo.edu.ar/ojs3/index.php/traslaciones/article /view/2002

Cubo de Severino Liliana, et al. (2007). Los textos de la ciencia. Córdoba, Argentina: Editorial Comunicarte.

Cuevas, A., Méndez, S. y Hernández-Sampieri, R. (2014). Introducción al estilo APA para citas y referencias (3a ed.). Universidad de Celaya, México. Recuperado de: http://www.udec.edu.mx/i2012/investigacion/investigaci on.html

Quintana, L. y Hermida J. (2020) Los proyectos de investigación en las tesinas de grado: Un enfoque sobre la investigación basada en textos. Aportes al derecho/ Revista Jurídica de Uflo Universidad. V. 4, N 4, pp. 12-25. http://revistajuridica.uflo.edu.ar/index.php/RevistaJuridica

Ramírez, T. (1999). Manual para la presentación de anteproyectos e informes de investigación. México. Oxford

UPEL (2016). Manual de Trabajos de Grado, de Especialización y Maestría y Tesis Doctorales. Universidad Pedagógica Experimental Libertados. $5^{\mathrm{a}}$ edición. Caracas. 

Universidad

Norbert Wiener 